\title{
Los «Templos en U» del valle de Huaura, costa norcentral. Una aproximación preliminar a un problema monumental
}

Les «Temples en U» de la vallée de Huaura, côte nord-centrale. Aproximation préliminaire d'un un problème monumental

The U-Shaped Temples of the Huaura Valley, northcentral coast. A preliminary approximation of a monumental problem

\section{Henry Tantaleán y María Ysela Leyva}

\section{OpenEdition}

Journals

Edición electrónica

URL: http://journals.openedition.org/bifea/1279

DOI: 10.4000/bifea.1279

ISSN: 2076-5827

Editor

Institut Français d'Études Andines

Edición impresa

Fecha de publicación: 1 diciembre 2011

Paginación: 459-493

ISSN: 0303-7495

Referencia electrónica

Henry Tantaleán y María Ysela Leyva, « Los «Templos en U» del valle de Huaura, costa norcentral. Una aproximación preliminar a un problema monumental », Bulletin de l'Institut français d'études andines [En línea], 40 (3) | 2011, Publicado el 01 junio 2012, consultado el 10 diciembre 2020. URL : http:// journals.openedition.org/bifea/1279; DOI : https://doi.org/10.4000/bifea.1279

\section{cc) (†) $\odot$}

Les contenus du Bulletin de l'Institut français d'études andines sont mis à disposition selon les termes de la licence Creative Commons Attribution - Pas d'Utilisation Commerciale - Pas de Modification 4.0 International. 


\title{
Los «Templos en U» del valle de Huaura, costa norcentral. Una aproximación preliminar a un problema monumental
}

\author{
Henry Tantaleán* \\ María Ysela Leyva**
}

\section{Resumen}

En este artículo se describen y analizan los edificios con planta en forma de $U$ del valle bajo del río Huaura conocidos también como Chacra Socorro o Huaura Antigua, ubicados en la actual provincia del mismo nombre en el departamento de Lima, costa norcentral del Perú. Estos edificios formarían parte de una tradición arquitectónica monumental que se extendió por los valles de la costa central durante la época Formativa Temprana (1800 ANE-900 ANE) y que tendrían como función principal congregar una gran cantidad de personas en sus plazas delimitadas por sus estructuras arquitectónicas. De la definición y análisis de este patrón arquitectónico han devenido una serie de explicaciones de las sociedades que lo construyeron. En este artículo estas se discuten a la luz de la presentación de los edificios de este y otros valles cercanos. Todo esto permite generar una visión diacrónica de la historia temprana del valle de Huaura y su región.

Palabras clave: costa norcentral, época Formativa, Huaura, «Templo en U», arquitectura monumental

* Universidad Nacional Mayor de San Marcos, investigador asociado al Instituto Francés de Estudios Andinos (IFEA UMIFRE 17, CNRS-MAE). E-mail: henrytantalean@yahoo.es

** Universidad Nacional Mayor de San Marcos. E-mail: marysela@hotmail.com 


\title{
Les «Temples en U» de la vallée de Huaura, côte nord-centrale. Aproximation préliminaire d'un un problème monumental
}

\begin{abstract}
Résumé
Cet article décrit et analyse les bâtiments à la base en forme de $U$ de la basse vallée du Huaura, également connus sous le nom de Chakra Socorro ou Huaura Antigua. Ils se trouvent dans la province du même nom, dans le département de Lima, au centre-nord de la côte du Pérou. Ces bâtiments font partie d'une tradition architecturale monumentale qui s'est répandue dans les vallées de la côte centrale au cours du Formatif ancien (1800 avant JC-900 av JC). Ils auraient eu pour fonction principale de rassembler une grande quantité de personnes au sein de places délimitées par des structures architecturales. De la définition et de l'analyse de ce modèle architectural découle une série de postulats sur les sociétés qui l'ont construit. Cet article les examine à la lumière de la description des bâtiments de cette vallée et d'autres vallées adjacentes. Tout cela permet d'avoir une vision diachronique de l'histoire ancienne de la vallée de Huaura et de sa région.
\end{abstract}

Mots-clés: la côte centre-nord, période Formatrive, Huaura, «Temple en U», architecture monumentale

\section{The U-Shaped Temples of the Huaura Valley, northcentral coast. A preliminary approximation of a monumental problem}

\begin{abstract}
In this paper, we describe and analyze the U-shaped monumental complexes from the lower Huaura valley known as Chacra Socorro o Huaura Antigua, located in the province of Huarura in the Department of Lima in the north-central coast of Peru. These constructions formed part of a tradition of monumental architecte that extended across the valleys of the central coast during the Early Formative Period (1800 a. C.-900 a. C.). They would have functioned to permit the congregation of large quanties of people in the central plazas bounded by its lateral structures. From the definition and analysis of this architectural pattern, there have arisen a series of explanations about the societies that constructed the complexes. In this article, we discuss these theories through the presentation of the $\mathrm{U}$-shaped architecture in the Huaura Valley and other nearby valleys. All of this permits to generate a diachronic view of the early history of the Huaura valley and its region.
\end{abstract}

Key words: northcentral coast, Formative period, Huaura, «U-Shaped Temple», monumental architecture

\section{INTRODUCCIÓN}

La explicación arqueológica de las sociedades tempranas de la costa norcentral prehispánica andina se encuentra en plena elaboración. A pesar de que esta región (espacialmente cercana a la actual capital del Estado peruano) tiene una larga historia de investigaciones científicas desde los inicios de la arqueología peruana a finales del siglo XIX (Reiss \& Stübel, 1880-1887; Uhle, 1991 [1903]) hasta la actualidad, todavía existen varias problemáticas que necesitan ser comprendidas y 
analizadas desde una perspectiva sistemática intra e intervalles. En ese sentido, la investigación de la emergencia de los primeros edificios monumentales en el periodo conocido como Arcaico Tardío o Precerámico Tardío (3000 ANE-1800 ANE) ha convertido a esta época en un tema de discusión sobresaliente. Esto ha sido posible, principalmente, por las investigaciones y aportes del Proyecto Caral dirigido por la Dra. Ruth Shady a mediados de la década de 1990 (Shady \& Leyva, 2003) y que han estimulado un importante debate que busca la comprensión de fenómenos sociales sincrónicos (Haas et al., 2005; Chu, 2006; 2008; Vega-Centeno, 2005a; 2005b; 2006; 2007; Creamer et al., 2007; Aguilar, 2006; Lumbreras, 2006; Makowski, 2008) e inmediatamente posteriores, no solamente en este área sino también en otras vecinas (véase Rick, 2006; Burger, 2008).

Si bien, la primacía del debate ha girado en torno a los edificios de mayor antigüedad y volumen, se cree que fenómenos sociales posteriores en valles vecinos también deben comenzar a ser explicados en base a la investigación de su propia trayectoria histórica, lo que contribuirá a obtener una visión diacrónica de las sociedades de estos valles y, por consecuencia, de la región. Por ello, resulta relevante comprender qué sucedió en el valle de Huaura, un valle cercano al de Supe (fig. 1), donde también se ha registrado la existencia de edificaciones asignables al Arcaico Tardío y al Formativo Temprano (Cárdenas, 1977b; Aguilar, 2006; Chu, 2006; Haas \& Creamer, 2006: 750; Creamer et al., 2007; Shady et al., 2009) y que, de hecho, se reconoce como integrante de un complejo o sistema de valles que conformarían una región o unidad geográfica y arqueológica denominada «Costa Norcentral» (Shady, 2006; Aguilar, 2006), «Norte Chico» (Creamer et al., 2007) o «Área Fortaleza-Huaura» (Pozorski \& Pozorski, 2008). Asimismo, se hace necesario retomar la historia de las ocupaciones tempranas sedentarias de este valle, puesto que las investigaciones en el valle de Huaura han sido enfocadas sobre todo en los periodos posformativos (Stumer, 1952; Cabrel, 1996; 2000; 2001; 2007; Ruiz, 2006; Shady \& Ruiz, 1979; Ruiz, 1981; 1991; Krzanowski, 1991a; Cruzado, 2008; Vallejo, 2009: 147-149; Dolorier \& Casas, 2009; Nelson \& Ruiz, 2010). Incluso, cuando se han realizado investigaciones sobre sitios arcaicos o formativos en este valle, la existencia de estos casi siempre se explica por asociación o dependencia de los fenómenos sociales de procesos históricos producidos en los valles cercanos (véase Shady, 2006: 70; Shady et al., 2009)1.

Por lo anteriormente señalado, este artículo se centrará en la problemática de la época denominada en la arqueología andina como el Formativo Inferior o Temprano (1800 ANE-900 ANE)2, y asociada en esta región con la tradición de «Templos en U», definida por Carlos Williams desde la década de 1970. Como

1 Para una historia de las investigaciones arqueológicas en el valle de Huaura se puede consultar Aguilar (2006: 52).

2 Según la periodización de Rowe, nuestra investigación se enmarcaría en el Periodo Inicial (1800 ANE900 ANE). En cualquiera de los casos, para nosotros estos periodos son solamente referenciales y no constituyen explicaciones a priori de fenómenos sociales por conocer. Para discusiones recientes sobre el uso de la categoría de Formativo se pueden consultar Kaulicke (2008) y Silverman (2009). 


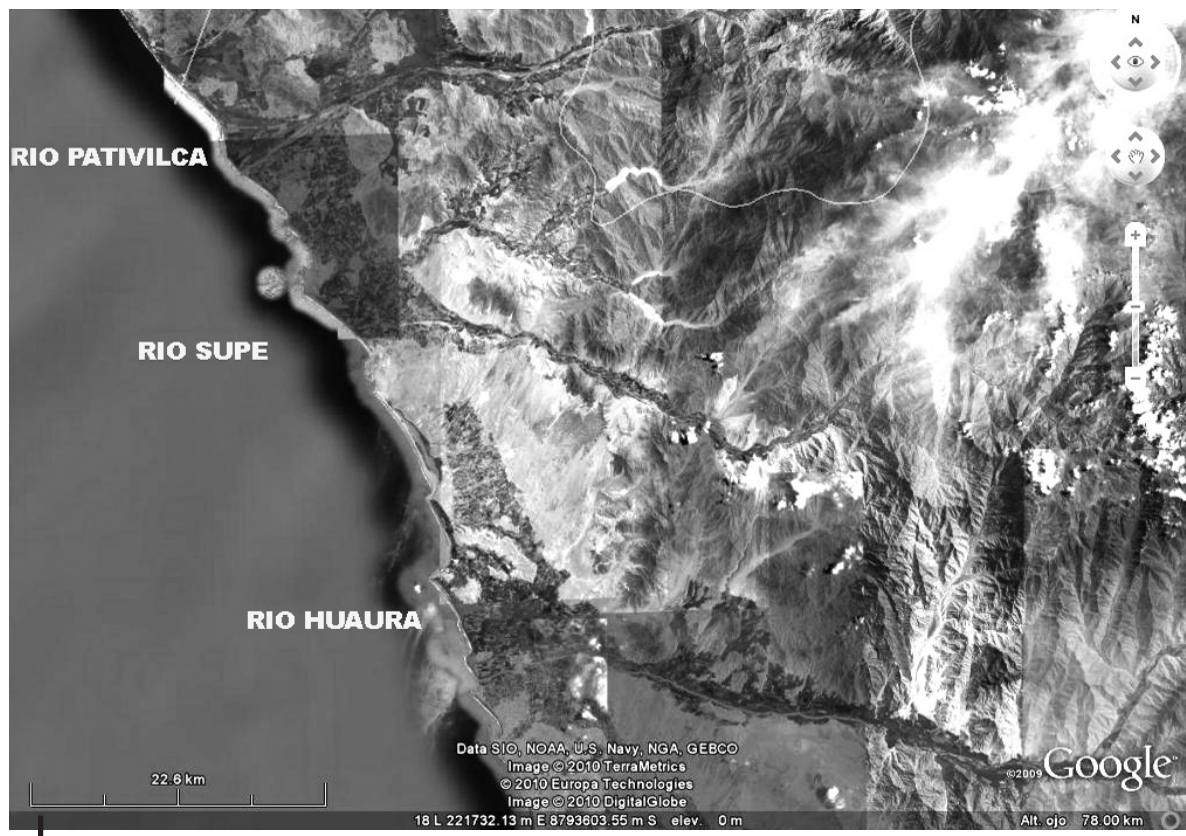

Figura 1 - Vista satelital de Google Earth donde se puede apreciar la localización de los valles de Huaura, Supe y Pativilca

un avance preliminar, este texto está basado en la información que se conoce por investigaciones precedentes, aumentado por nuestras observaciones recientes del sitio arqueológico. De todo este trabajo acumulado se desprenden una serie de apreciaciones y esbozos explicativos con relación a los fenómenos sociales del Formativo en la costa norcentral del Perú.

\section{LOS «TEMPLOS EN U» DE LA COSTA CENTRAL Y NORCENTRAL: PROBLEMÁTICA Y PLANTEAMIENTOS}

Desde la década de 1970, la arquitectura monumental en los periodos tempranos (Arcaico Tardío y Formativo) de la costa central peruana ha sido clasificada mediante la definición de patrones arquitectónicos, los cuales reúnen edificios con características morfológicas análogas dentro de espacios geográficos amplios. De esta manera, se ha planteado la existencia de «tradiciones arquitectónicas» como los «edificios de plataformas escalonadas alineadas longitudinalmente» (tipo Las Haldas) (Matsuzawa, 1978; Álvarez \& Espinoza, 1997), los edificios del «patrón Casma» (Williams, 1980b; Bazán, 2008), los edificios «piramidales con plaza circular hundida» (tipo Caral) (Williams, 1972; Moseley, 1992: 137; Burger, 1992: 75) y los «Templos en U» (Williams, 1971; 1980a; 1980b; 1985; Kaulicke, 2008: 208). 
Fue Carlos Williams quien planteó la existencia del patrón arquitectónico de los «Templos en U» para la costa central (Williams, 1980a; 1980b) (figs. 2, 3 y 4) basándose en el análisis de fotografías aéreas y reconocimientos de campo. Posteriormente su planteamiento y sus implicancias socioeconómicas y sociopolíticas, han sido retomados por diferentes investigadores en el área andina (Fung, 1987; Bonavia, 1991; Moseley, 1992: 138; Moore, 1996; Von Hagen \& Morris, 1998; Canziani, 2009)3. Sin embargo, este modelo no ha sido intensivamente comprobado mediante investigaciones arqueológicas sistemáticas $y, \quad$ consecuentemente, algunas interpretaciones funcionales de los sectores de estos edificios quedaron por definir. Tal fue el caso, por ejemplo, de la función asignada a las plazas centrales que se encuentran entre los brazos del edificio, las cuales según Williams (1980a: 415) tenían la función de «campos de cultivo rituales» y no servían para congregar multitudes. Sin embargo, gracias a investigaciones que incluían excavaciones de dichos sectores, tal función fue descartada en el sitio de Cardal en el valle de Lurín (Burger, 1993), en Garagay en el valle del Rímac (Ravines \& Isbell, 1976) y en San Jacinto en el valle de Chancay (Carrión, 2000).

Otra cuestión muy importante por resolver empíricamente es la historia de la construcción de estos edificios ya que Williams solamente nos presentó una secuencia arquitectónica evolutiva de los mismos basándose en la morfología y degeneración de la forma arquitectónica

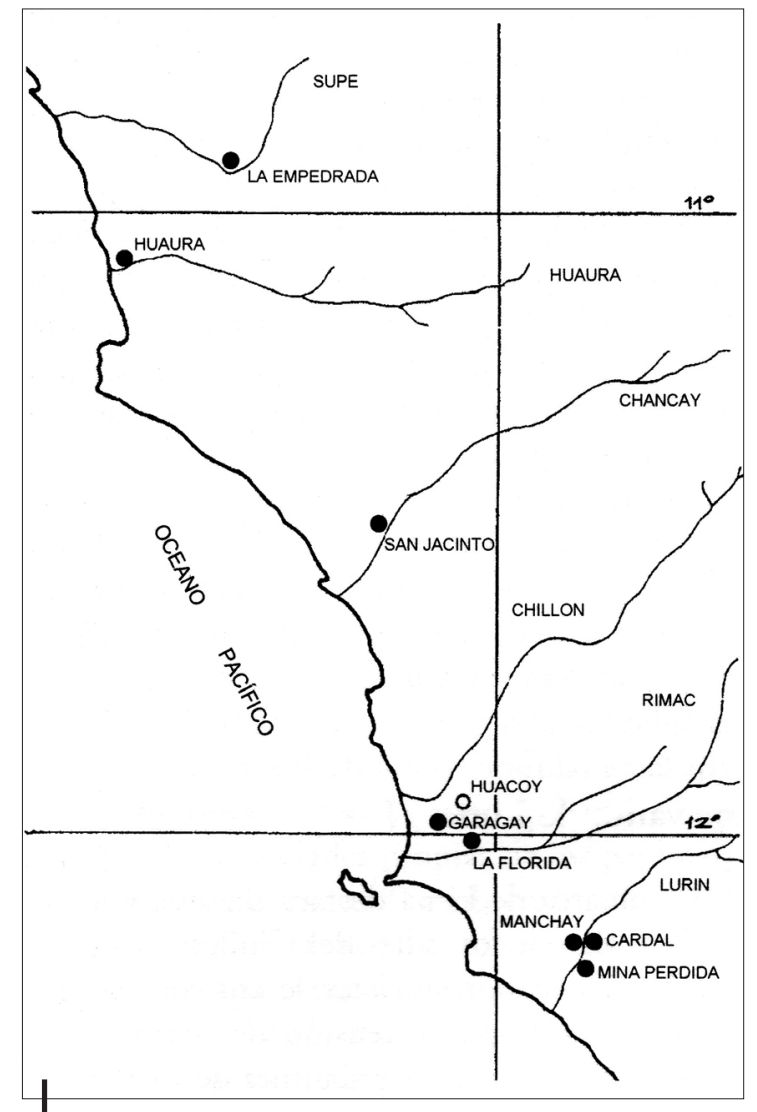

Figura 2 - Mapa de la costa central con la ubicación de los complejos con planta en U

Nótese la indicación de los sitios de Supe y Huaura (según Canziani, 2009: 148, fig. 155)

3 Desde que se plantea que estos edificios son «Templos» ya se le estaría asignando una función social a priori netamente religiosa o ceremonial, una tradición explicativa muy extendida en la arqueología andina y, sobre todo, en los periodos más tempranos (véase, por ejemplo, Siveroni, 2006; Rick, 2006). De esta manera, se ha asignado esta función a los sitios monumentales tempranos aunque en muchos casos todavía no se ha definido empíricamente qué tipo de prácticas sociales se dieron en dichos complejos arquitectónicos y alrededor de estos. En este artículo se mantiene la denominación de «Templo» por ser la más difundida en la literatura arqueológica aunque se prefiere denominarlos como «Edificios con planta en forma de U». 


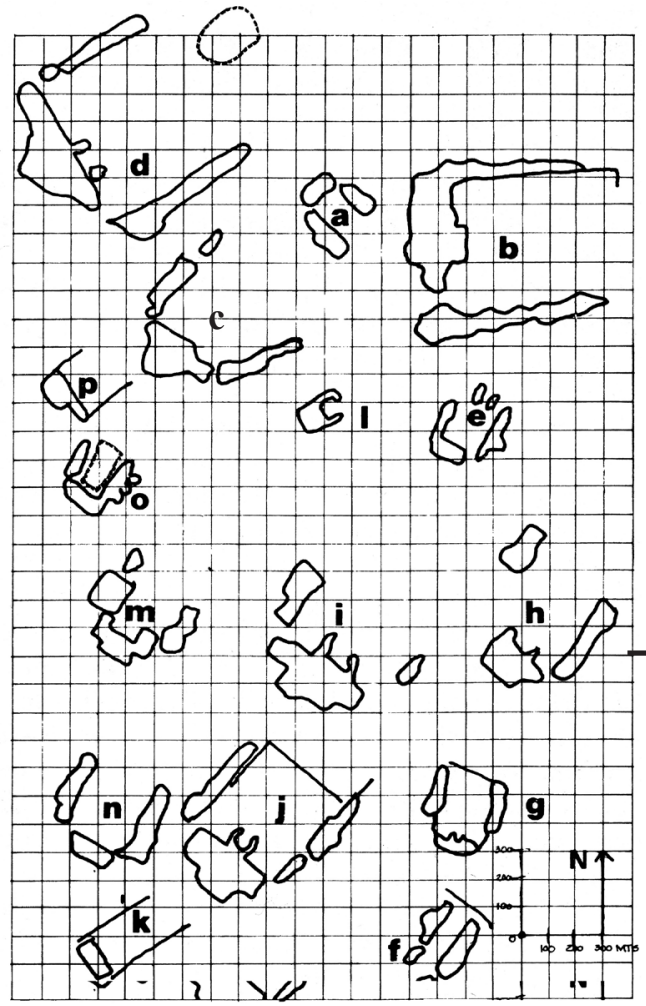

Figura 3 - Algunos de los complejos con planta en $U$ de la costa central desde Supe a Mala

a) La Empedrada, Supe; b) Huaura; c) Miraflores, Chancay; d) San Jacinto, Chancay; e) Porvenir, Chancay; f) Paraíso, Chillón; g) Chocas, Chillón; h) Huacoy, Chillón; i) Garagay, Rímac; I) Pampa de Cueva, Rímac; m) Manchay, Lurín; n) Mina Perdida, Lurín, o) Cardal, Lurín; p) Salitre, Mala Según Williams, 1980b: 412, fig. 2.5

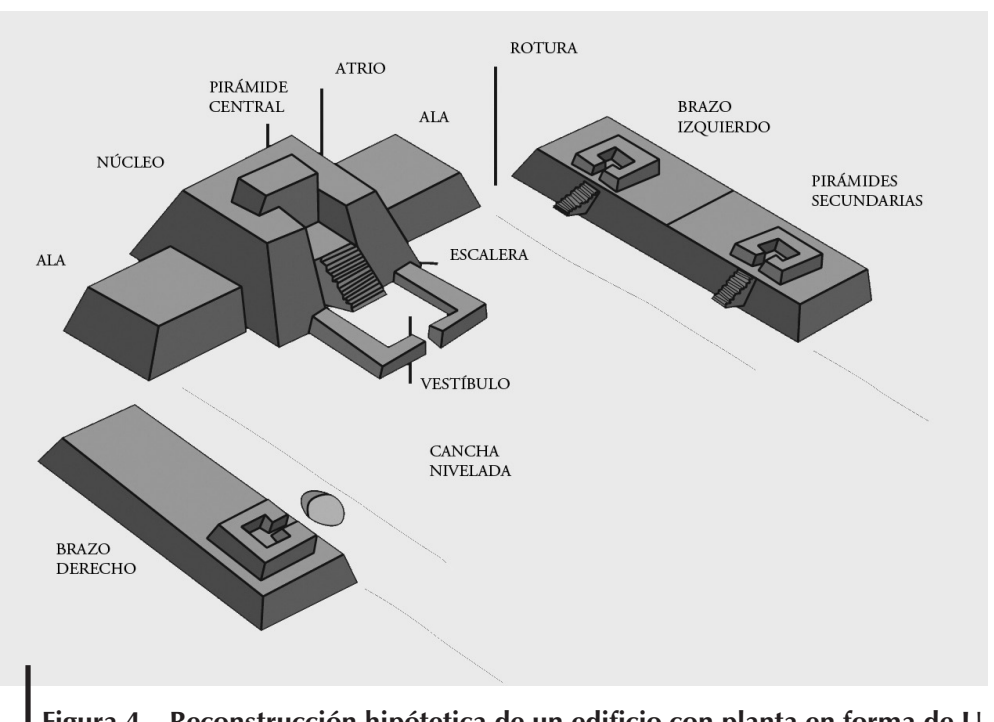

Figura 4 - Reconstrucción hipótetica de un edificio con planta en forma de $\mathbf{U}$ Según Silva, 2000 en base a Williams, 1980: fig. 2 
original (Williams, 1980a; 1985), sin interpretar los eventos sociales que llevaron a la edificación de estas estructuras. Otro tema importante y que se articula con el anterior corresponde a la extensión espacial de dicha tradición arquitectónica. Con respecto a esto último, Williams (1980a: 410) planteaba que el límite sur del patrón se encontraba en la desembocadura del valle de Mala, en la actual provincia de Cañete, lo cual ha seguido manteniéndose en diferentes publicaciones contemporáneas (Bonavia, 1991: 181; 2007 [2003]: 146; Pozorski \& Pozorski, 1992: 846; 2008: 612; Silva \& García, 1997: 219; Silva, 2000; Narváez, 2006: 124; Kaulicke, 2008: 140) (fig. 3). Sin embargo, mediante nuestras investigaciones en este valle se ha podido definir que el sitio señalado por Williams como un edificio con planta en $U$ y plaza circular hundida conocido como El Salitre no formó parte de esta tradición arquitectónica (Tantaleán \& Pinedo, 2004; Pinedo, 2008). De hecho, al comparar sus características constructivas, planimétricas y de emplazamiento con los otros edificios en discusión, no se encuentra ninguna semejanza que permita seguir asociándolo con la época Formativa.

En este sentido, también resulta llamativo que el límite septentrional o norte de dicha tradición arquitectónica no haya sido definido empíricamente hasta la actualidad4. Si bien, Williams señala que esta tradición se extendería por el norte hasta el valle de Supe y estaría representado en el sitio La Empedrada o Sitio 22i 13B03 (Williams \& Merino, 1979: 263; Burger, 1992: 76) (fig. 5), los trabajos realizados en este valle durante las últimas décadas han estado mayormente enfocados en los periodos previos, particularmente en el periodo Precerámico Tardío o Arcaico Superior, sobre todo, en los sitios monumentales asociados al Arcaico Tardío (Shady \& Leyva, 2003; Pozorski \& Pozorski, 2008: 610; Shady et al., 2009) por lo que no se conoce nada sustancial de este sitio o alguno temporalmente cercano al Formativo.

De este modo, salvo algunas observaciones superficiales muy preliminares realizadas por Navarro (1993), se hace importante resolver si el sitio de La Empedrada fue un edificio con planta en forma de $U$ o no. Por el momento, a la luz del modelo planteado por Williams, los sitios ubicados en el valle de Huaura son los mejores exponentes del límite norte de dicha tradición5 ${ }^{5}$, de hecho, el Edificio A que describiremos más adelante posee la plaza principal más grande (24 ha) de esta tradición arquitectónica6.

Asimismo, Ilama la atención, dadas las grandes dimensiones de los edificios con planta en forma de $U$ de Huaura, que estos no hayan sido objeto de estudios

4 Algunos autores (Pozorski \& Pozorski, 1992: 865; Dillehay, 2006) también utilizan la denominación de edificio o estructura con planta en $U$ para construcciones contemporáneas más norteñas. Sin embargo, estas son semejanzas formales arquitectónicas de sociedades con historias diferentes (aunque no necesariamente disociadas) a las que veremos aquí.

5 También resulta interesante que el sitio de La Empedrada se halla en una quebrada que conecta el valle de Supe con el de Huaura, lo que enfatizaría el planteamiento de que la rutas intravalles mediante esas quebradas también sean importantes para la relación de las sociedades que las habitan.

6 Aunque sea un lugar común en la arqueología de la costa central, el «Templo en U» más grande es el de San Jacinto en Chancay (véase fig. 14). Sin embargo, este tiene una plaza de 21 ha. 


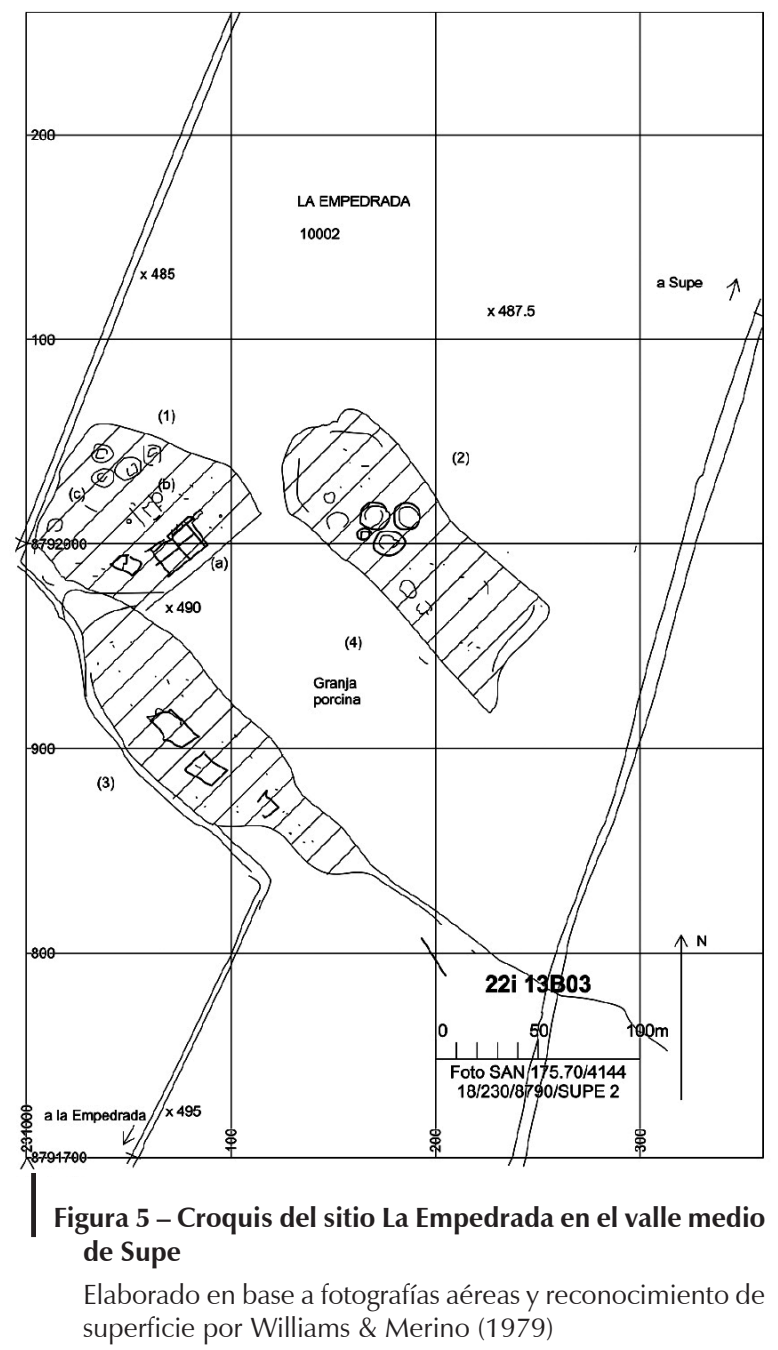

sistemáticos sino que solo existan referencias puntuales sobre este sitio7. De hecho, si uno repasa la información existente para los edificios con planta en forma de $\mathrm{U}$ de la costa central se da con la sorpresa que realmente nuestro conocimiento del periodo Formativo de esta zona es bastante reducido. Salvo el programa de investigación arqueológica de Richard Burger (1992; 2009a) en el valle de Lurín (justamente en el límite opuesto de esta tradición arquitectónica), los demás sitios solamente han merecido investigaciones puntuales (véase Scheele, 1970; Ravines \& Isbell, 1976; Ludeña, 1970; 1973; Patterson, 1985; 1991; Silva, 1998; Mesía, 2000; Carrión, 2000; Silva \& Jaime, 2000).

7 Como las de los catastros de Miasta \& Merino (1986), Cárdenas (1977b; 1988), Nelson \& Ruiz (2005), Brown (2008), Asencios (2009) o textos ubicados en internet (Jacobs, 2000; Valdez, 2007). 
Por lo anteriormente expuesto, este artículo espera ofrecer una contribución para retomar y profundizar en la problemática de la monumentalidad prehispánica andina temprana, en particular en la costa central y norcentral.

\section{EL VALLE BAJO DEL RÍO HUAURA}

El valle de Huaura se ubica a $148 \mathrm{~km}$ al norte de la ciudad de Lima, en la provincia de Huaura, departamento de Lima (figs. 1 y 2). Este valle representa una unidad geográfica de mucha importancia en la región natural Costa o Chala y Yunga (Pulgar Vidal, 1976). El valle de Huaura es típico de la vertiente occidental de los Andes cuyas aguas fluyen desde las alturas hasta desembocar en las aguas del Océano Pacífico. Este río nace en el nevado de Raura, al noreste de la región Lima, entre los límites de Huánuco y Pasco. Además de fuente de agua, en su incesante fluir se ha abierto paso por entre las estribaciones andinas convirtiéndose en un corredor natural que une la costa con la sierra y acerca a las poblaciones que por ahí ascienden a los Andes desde la costa con la región amazónica en el área cercana del Paso de Oyón. La cuenca del río Huaura cubre unos 4400 km², siendo su volumen máximo de descarga hídrica de 100 m³/seg y el mínimo de 7 m³/seg (Aguilar, 2006: 16).

Este valle se caracteriza por presentar en su sección inferior un cono deyectivo de regulares dimensiones, donde en la actualidad se observan grandes extensiones de terrenos agrícolas. Estas a su vez también cubren casi la totalidad del fondo aluvial del valle, gracias a la construcción de sistemas de irrigación que aprovechan el caudal permanente y considerable del río. Esto ha modificado el paisaje puesto que en general se trata de una zona desértica como se puede apreciar en la zona de Huacho o Végueta que, salvo filtraciones de agua dulce o humedales, no posee mayores ecosistemas aprovechables en tierra firme por los seres humanos. Por eso, la construcción del paisaje actual, sobre todo mediante canales de irrigación, puede haber comenzado muy temprano y haberse incrementado desde la época formativa.

\section{LOS EDIFICIOS CON PLANTA EN FORMA DE U DEL VALLE BAJO DE HUAURA}

Los edificios con plantas en forma de $U$ de Huaura, también conocidos como la zona arqueológica de Chacra Socorro8 ${ }^{8}$ y/o Huaura Antigua, se hallan ubicados en un área llana de la margen norte del valle bajo del río, muy cercanos al cauce actual y a unos 2,30 km de la orilla del mar (fig. 6). La margen norte del valle en esta zona es más elevada que la opuesta aunque, gracias a canalizaciones río arriba, es cultivable. Así pues, ambos edificios se hallan emplazados en un área que habría estado beneficiada por el agua y asociada seguramente, como lo es en la actualidad, a campos de cultivo sobre los que se elevaban las estructuras

8 Declarado bajo ese mismo nombre como «Patrimonio Cultural de la Nación» mediante Resolución Directoral Nacional n. ${ }^{\circ}$ 460, emitida el 30 de marzo de 2006. 


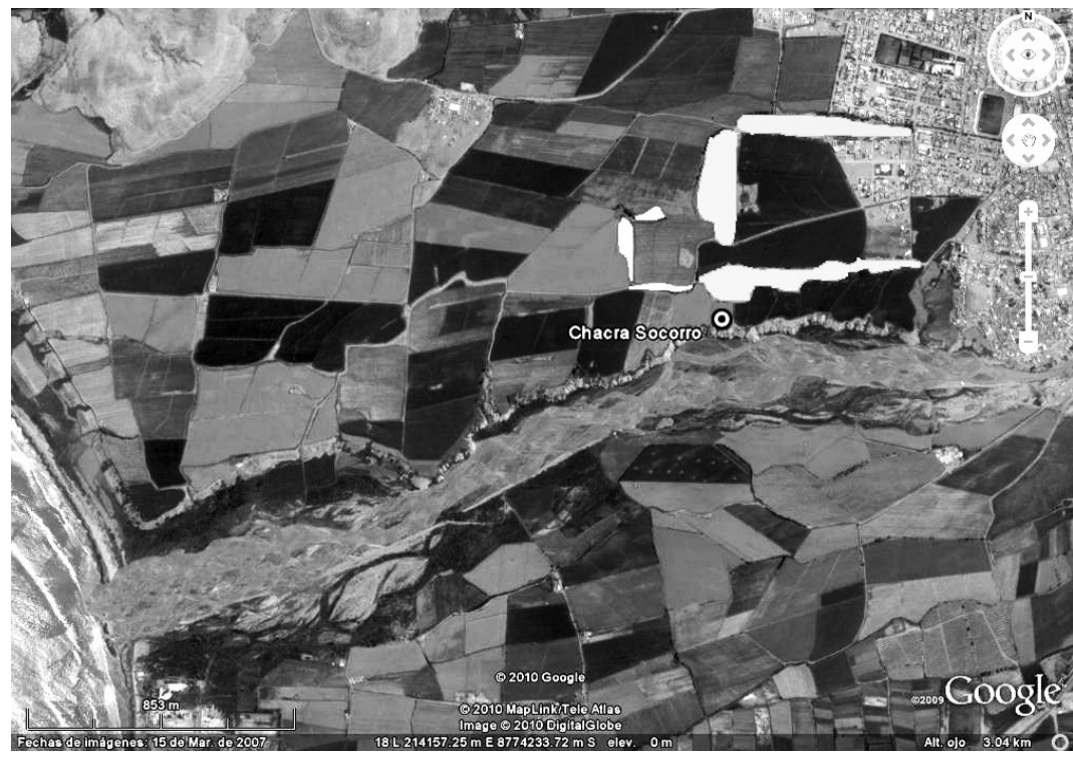

Figura 6 - Vista satelital donde se ha resaltado la silueta de los edificios con planta en forma de $U$ en el valle bajo de Huaura, también conocidos como Chacra Socorro

Nótese su ubicación muy cercana al cauce del río, la desembocadura del mismo en el Océano Pacífico y el avance de la ciudad moderna de Huaura

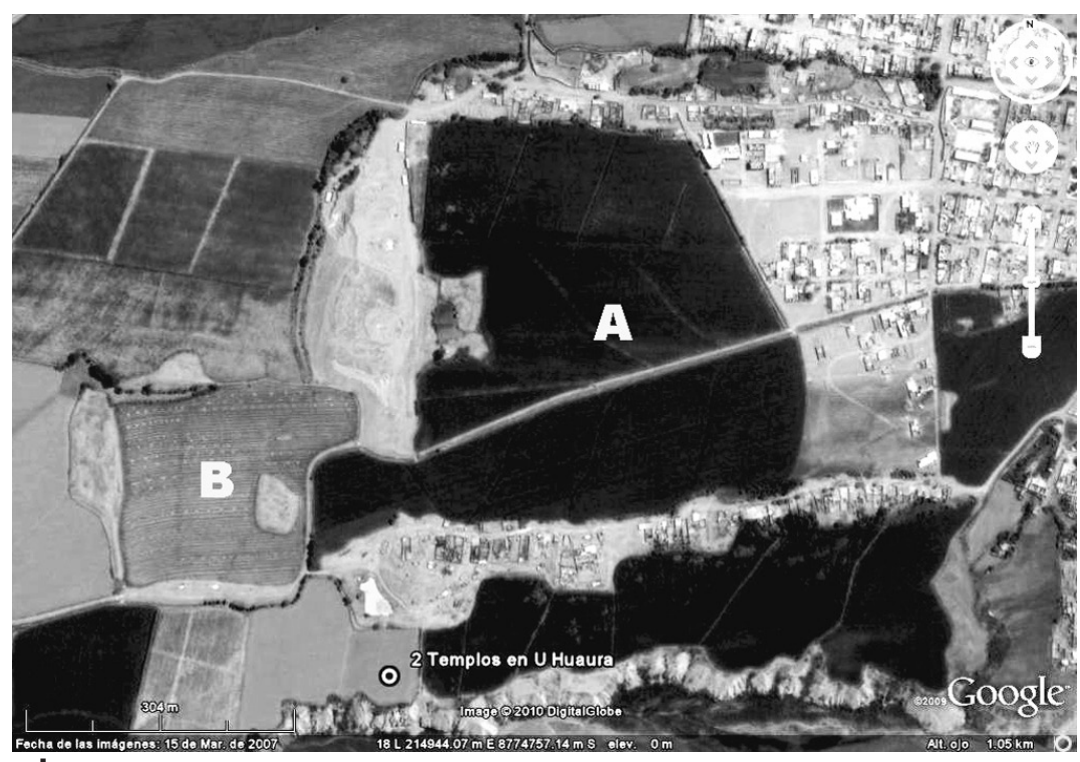

Figura 7 - Vista satelital de Google Earth de los Edificios A y B o edificios con planta en forma de $U$ de Huaura

Se puede ver cómo la ocupación humana contemporánea está ingresando y superponiéndose a las estructuras arquitectónicas y a la plaza central del Edificio A 
arquitectónicas. Asimismo, la elevación de esta margen supondría que los edificios cuentan con una mayor visibilidad de las tierras circundantes y del río e, incluso, del mar. Ambos edificios están orientados paralelamente al cauce del río y los brazos están abiertos en un eje de unos $90^{\circ}$.

Para poder disgregarlos y describirlos de manera adecuada los denominamos Edificio A y Edificio B. El Edificio A tiene mayores dimensiones, y el Edificio B está ubicado detrás del montículo principal del Edificio A y al oeste del mismo, de dimensiones menores.

Ambos edificios mantienen la composición típica de un edificio con planta en forma de $U$; es decir, poseen dos plataformas paralelas o brazos que se unen en uno de sus extremos a un montículo principal más elevado y abultado que los laterales, lo que que genera un gran espacio delimitado denominado plaza central.

En la actualidad, los brazos del Edificio A se hallan ocupados por viviendas precarias y la plaza es utilizada como campo de cultivo por lo que, obviamente, se halla alterada de manera superficial. Mientras que el Edificio B se halla mejor conservado, quizá por sus menores dimensiones y su ubicación todavía alejada del núcleo urbano de la Huaura actual (fig. 7). Alrededor de estos dos grandes edificios se pueden observar otros montículos que formarían parte de otras acumulaciones arquitectónicas y/o probablemente domésticas.

En algunos cortes y en la parte superior de las estructuras se puede observar que existen estructuras rectilíneas hechas con cantos rodados y barro. Estos fueron notados tanto en los montículos principales como en los brazos de ambos edificios. Los cantos rodados son un material que se encuentra disponible en el mismo sitio dado que nos encontramos en pleno cono deyectivo del río Huara (fig. 8). También se ha reportado (Cárdenas, 2004b; Valdez, 2007) la utilización de bolsas hechas con cuerdas de totora conteniendo piedras y otros materiales orgánicos como forma de relleno para ganar volumen llamadas shicras. La utilización de estas shicras como parte de los rellenos constructivos en edificios monumentales es una tecnología que se origina en el Arcaico Tardío pero que se mantiene en los edificios del Formativo de la costa norcentral y central (Bonavia, 1982: 267; Burger \& Salazar, 2009; Asencios, 2009). Sin embargo, en la actualidad todos los sectores de los edificios se encuentran cubiertos por una gran cantidad de cantos rodados, lo que no permite reconocer las estructuras subyacentes salvo en los casos en que esta ha sido modificada

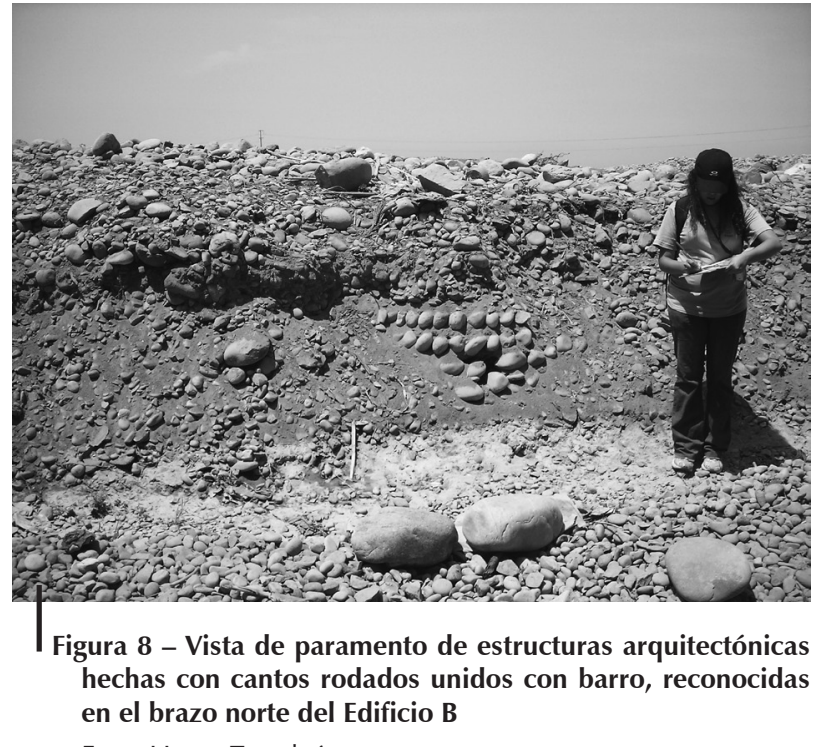

Foto: Henry Tantaleán 
Henry Tantaleán, María Ysela Leyva
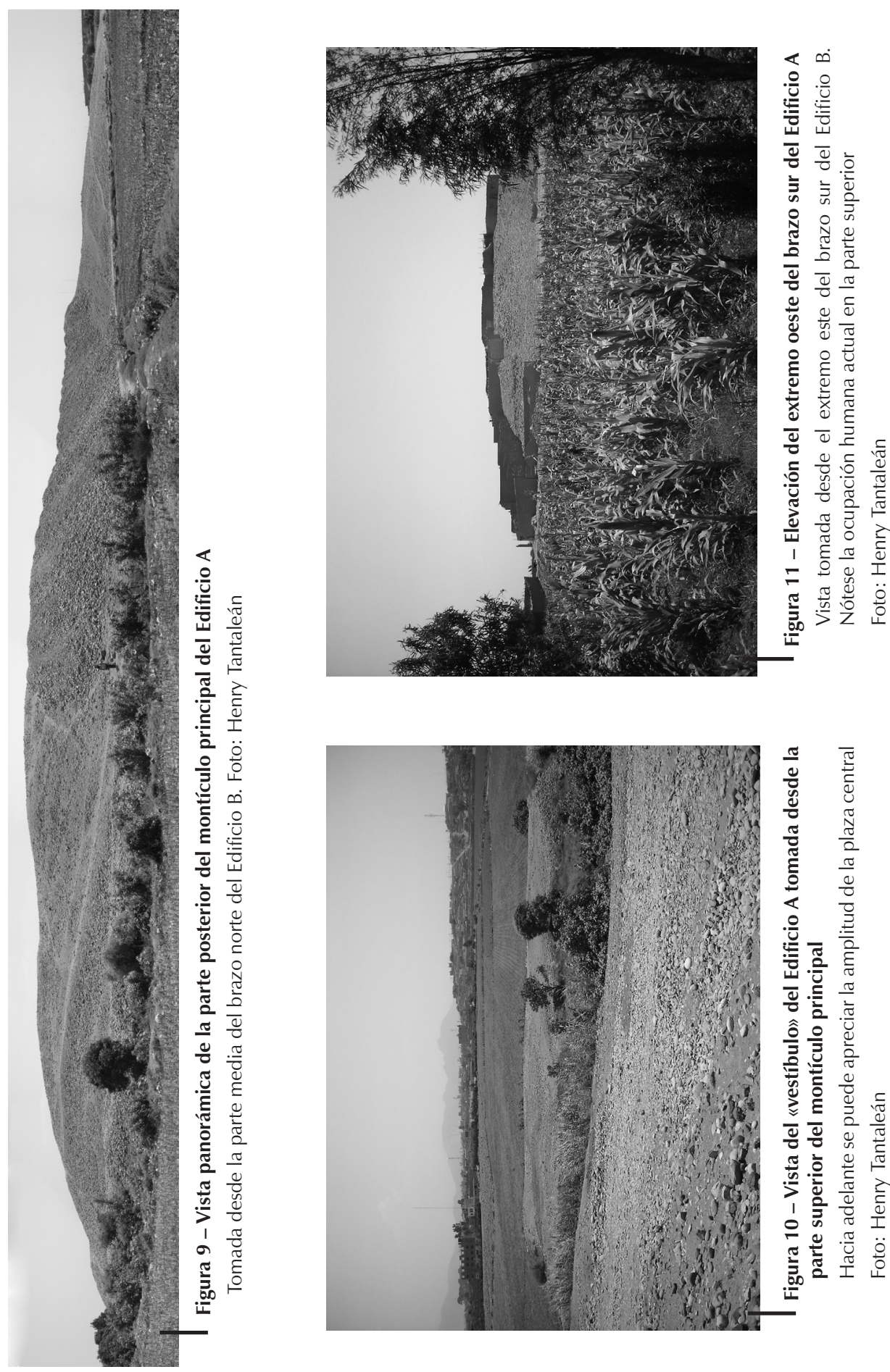
o disturbada recientemente. La acumulación de cantos rodados se podría deber, en primer lugar, a un evento de «entierro» después de su abandono y, en segundo lugar, a la acumulación de piedras extraídas de los campos de cultivo de los alrededores y depositadas sobre los edificios hasta la actualidad.

\section{1. Descripción del Edificio A}

\section{1. 1. Montículo principal o plataforma central}

Tiene una longitud total en la parte frontal de unos $380 \mathrm{~m}$ y está orientado siguiendo un eje norte sur (entre $0-2^{\circ}$ ). Se eleva unos $8 \mathrm{~m}$ sobre el nivel de la plaza central y tiene una planta hemicircular con el frontis más recto y regular que la parte posterior. Parece que se han realizado adiciones al volumen principal a lo largo de su historia constructiva, lo que también se puede expresar en la existencia de las denominadas «alas». Es decir, se construyó un volumen principal al cual se le añadieron o adicionaron lateralmente plataformas más pequeñas, quizá también sobre una plataforma baja se superpuso una posterior. En este caso, el volumen principal mide unos $230 \mathrm{~m}$ de largo y unos $140 \mathrm{~m}$ de ancho (fig. 9). En la parte central y más elevada del montículo y orientada hacia la plaza central tiene una serie de grandes depresiones con una central de una profundidad de unos $3 \mathrm{~m}$ que indicaría la presencia de un «atrio».

En la base del frontis principal del montículo se puede observar una plataforma rectangular con una depresión central que serían los indicios de la existencia de un «vestíbulo», formado por dos muros paralelos que se proyectan unos $60 \mathrm{~m}$ hacia el este y un muro de unos $80 \mathrm{~m}$ orientado de norte a sur que une ambos con una abertura que daría acceso a este espacio rectangular (fig. 10). Desde allí, se originaría una escalinata hacia la parte superior del montículo, hasta el «atrio» localizado en la parte superior de este.

Aunque la parte norte del montículo principal ha sido removida para la construcción de dos pabellones del Cementerio Nuevo Municipal de Huaura y cubierto con desmontes y escombros, la parte principal del montículo parece no haber sufrido mucho daño, aunque es de esperar que dicho cementerio se extienda en los siguientes años.

\section{1. 2. Los brazos laterales}

Ambos brazos se hallan orientados de Oeste a Este, estrechándose a medida que se alejan del montículo principal. El brazo norte tiene una longitud aproximada de $600 \mathrm{~m}$ y una orientación regular de 93․ Posee una altura variable de 3-4 m del suelo actual. Sin embargo, esta altura está condicionada por la destrucción y ocupación moderna. Por su parte, el brazo sur alcanza unos 750 m de longitud. Está alejado unos $50 \mathrm{~m}$ del montículo principal dejando un espacio abierto ofreciendo un acceso a la plaza central del Edificio B que describiremos luego. Este brazo se halla bastante elevado en comparación al brazo norte y por su ubicación ofrece una visión mayor del río que se encuentra a unos metros al sur (fig. 11). 
A diferencia del brazo norte que marca un ángulo casi recto con el extremo del montículo principal, el brazo sur se orienta unos cuantos grados hacia el norte a medida que se aleja del montículo principal en un eje general de $86^{\circ}$.

\section{1. 3. La plaza central}

El montículo principal y los brazos norte y sur encierran un espacio de forma rectangular que suponen una superficie con un área aproximada de 240000 $\mathrm{m}^{2}$; es decir, 24 ha aproximadamente, resultando una de las plazas más extensas de la tradición arquitectónica de edificios con planta en $U$ de la costa central, superando incluso al sitio de San Jacinto localizado en el valle bajo de Chancay. En la actualidad, gran parte de la plaza es utilizada como campo de cultivo y la parte este o de ingreso a la plaza se halla ocupado por viviendas bastante consolidadas que forman el asentamiento humano Villa del Mar (fig. 10).

Se tiene referencias de miembros del equipo que acompañó a Nelson y Ruiz en su prospección del valle, de la existencia de una plaza circular hundida en la plaza (Miguel Aguilar, comunicación personal). Sin embargo, en nuestras visitas al sitio nosotros no la hemos podido ubicar, lo que puede deberse a que en la actualidad el área es un campo de cultivo.

\section{2. Descripción del Edificio B}

El Edificio B se halla ubicado muy cercano a la esquina suroeste del Edificio A y presenta menores dimensiones que este, tanto en extensión, volumen y altura (fig. 12). Mantienen la misma conformación que el Edificio A (brazos laterales, montículo principal y plaza central) los que pasamos a describir sintéticamente a continuación.

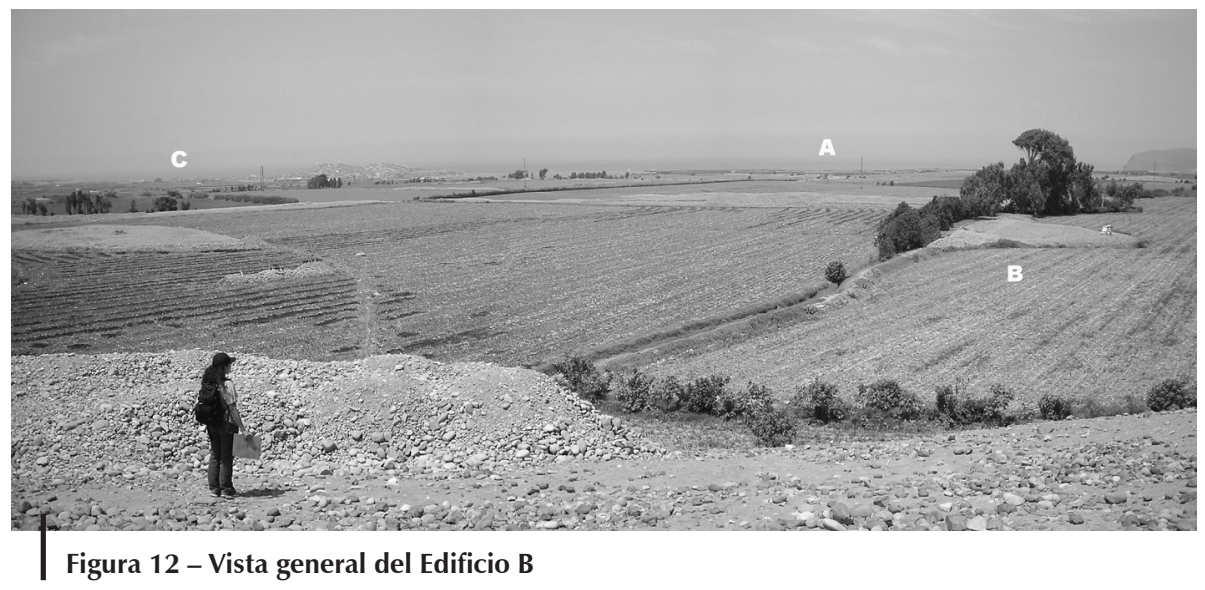

Vista tomada desde la cima del montículo principal del Edificio A. Se pueden notar los principales sectores del edificio: A) Montículo principal; B) Brazo norte; y, C) Brazo sur

Foto: Henry Tantaleán 


\section{2. 1. Montículo principal o plataforma central}

El montículo principal tiene una longitud total de unos $220 \mathrm{~m}$ y una orientación de $356^{\circ}$. Presenta un volumen mayor en la parte norte con un largo aproximado de $145 \mathrm{~m}$. Morfológicamente, la parte extrema sur es más delgada teniendo un ancho de unos $10 \mathrm{~m}$, mientras el volumen del montículo principal tiene un largo de $140 \mathrm{~m}$ y un ancho máximo de $58 \mathrm{~m}$. La altura actual de este sector es de unos $3 \mathrm{~m}$ y hay indicios en la parte superior de estructuras rectilíneas hechas con cantos rodados y barro (fig. 13). Al parecer este nunca se elevó más que lo que se observa en la actualidad. Asimismo, no hay indicios de un «vestíbulo» ubicado en la parte frontal, como en el caso del montículo principal del Edificio A.

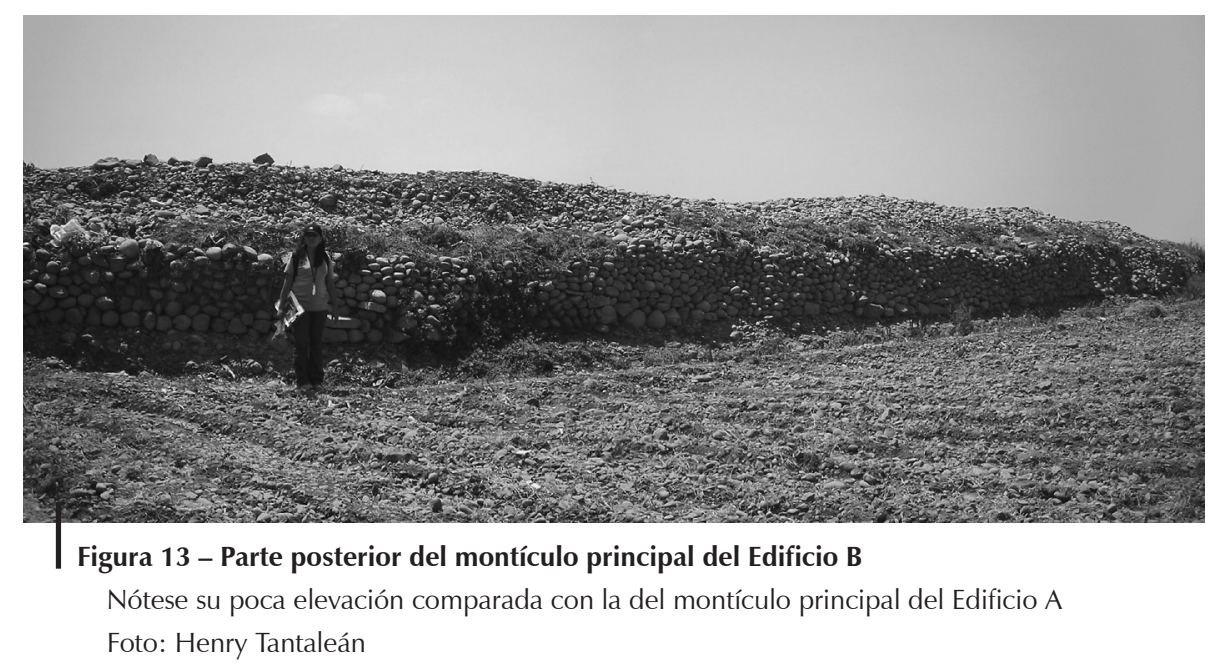

\section{2. 2. Los brazos laterales}

Ambos brazos no superan la altura de $2 \mathrm{~m}$. El brazo sur se une directamente con el montículo principal y tiene unos $200 \mathrm{~m}$ de largo con un ancho que oscila entre los 13-24 m, engrosándose en la parte media. Ambos presentan una orientación de unos $90^{\circ}$.

El brazo norte es corto en comparación al del sur y no se une directamente con el montículo principal, dejando abierto un espacio de unos $10 \mathrm{~m}$. Presenta mayor volumen en la parte extrema este alcanzando una longitud total de unos 105 $\mathrm{m}$, un ancho máximo de 38 metros y un ancho mínimo de $10 \mathrm{~m}$ cercano al montículo principal. Tiene una orientación general de $86^{\circ}$.

\section{2. 3. La plaza central}

El montículo principal y los brazos norte y sur encierran un espacio de forma cuadrangular en el ángulo suroeste mientras que en la parte norte tiene más apertura dada la longitud menor del brazo norte. En total, esta plaza tiene una superficie aproximada de $40000 \mathrm{~m}^{2}$ equivalente a 4 ha, una sexta parte que la del Edificio A. 


\section{3. Discusión cronológica de los edificios con planta en U de Huaura}

En una reciente síntesis de la arqueología de la costa norcentral (Chu, 2008) Ilama la atención la inexistencia de fechados de la época Arcaica o Precerámica Tardía relacionados con sitios arqueológicos ubicados en la margen norte del valle de Huaura. De hecho, en esa publicación, para todo el valle de Huaura solo se mencionan tres sitios tempranos: Bandurria, Paraíso 1 y río Seco de León (Chu, 2008: 33; Cárdenas, 2004a [para el sitio Paraíso 1]), todos ellos bastante alejados del río Huaura.

Los dos únicos fechados que tenemos para el sitio Chacra Socorro fueron obtenidos por Mercedes Cárdenas mediante el desaparecido laboratorio de radiocarbono de la Pontificia Universidad Católica del Perú (Ziółkowski et al., 1994: 397, 399). Los dos provienen del sitio que se denomina genéricamente como «Chacra Socorro» y que correspondería a nuestro Edificio A. La primera muestra fechada

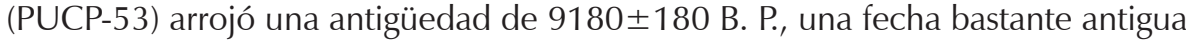
y que no correspondería con la época en la que planteamos que se erigiría el edificio. La segunda muestra fechada (PUCP-70) se dató en 3390 80 B. P., una fecha más coherente y que colocaría al sitio en el periodo Formativo Temprano (1800 a. C.-900 a. C.). Sin embargo, en la publicación de los fechados referidos (Ziółkowski et al., 1994) no se ofrece información del tipo de muestra datada ni se especifica el sector, lugar o contexto exacto de la excavación de donde procede la muestra. Como otros autores (Velarde, 1998; 1999; Kaulicke, 2000; León, 2006; 2007; Vega-Centeno, 2008; Castro et al., 2009: 148) han señalado, las dataciones radiocarbónicas deben ser utilizadas con prudencia y, sobretodo, conocer el tipo de muestra, las asociaciones arqueológicas y ser calibradas de manera adecuada. En ese sentido, deberemos seguir trabajando en subsanar estas cuestiones y conseguir muestras bien contextualizadas y cruzadas con otros métodos de datación relativa como secuencias morfotipológicas cerámicas producto de excavaciones controladas.

Por otra parte, en nuestros recorridos por el sitio Chacra Socorro, tanto en el Edifico A como en el Edificio B, no se ha observado una cantidad significativa de cerámica formativa (salvo un borde de olla sin cuello) que nos permita hacer una correlación estilística con otros sitios formativos del área o región. Así que este indicador cronológico relativo, aunque relevante, por ahora nos está vedado hasta que realicemos excavaciones arqueológicas que asocien las estructuras arquitectónicas con cerámica en uso.

Así pues, se cree que existen dos cuestiones muy importantes por definir en un futuro cercano: 1) El momento inicial de la construcción del sitio y 2) La historia de construcción de los Edificios A y B.

Con respecto al momento inicial de construcción del sitio, a la espera de más fechados radiocarbónicos, se puede plantear que por la morfología, tecnología y ubicación en el paisaje descrito, ambos edificios de la margen norte del valle de 
Huaura pertenecerían a la tradición de edificios con planta en forma de $U$ de la costa central del Formativo Inferior o Temprano que ya Williams había definido en los años 1970 y que se iniciaría a partir del 1800 a. C.9.

Para la zona del valle de Huaura, esto se daría posteriormente a las disturbaciones medioambientales que marcaron el paisaje de esta zona a finales del Arcaico Tardío entre los años 3800 y los 3600 cal B. P. (Sandweiss et al., 2009) y que provocarían visiblemente la cobertura del valle bajo con una gran cantidad de arena, áreas que fueron potencialmente cultivables en esos tiempos (fig. 14). Este proceso que incluiría terremotos, el fenómeno de El Niño y la arenización de las tierras agrícolas10 habría impulsado una crisis en los grupos sociales del Arcaico Tardío que habían construido y utilizado sitios como Caral, Vichama o Bandurria (Shady et al., 2009; Chu, 2008)11. Independientemente que esos procesos naturales hayan sido la causa del colapso de Caral y otras sociedades contemporáneas, también hubo un gran cambio social en el área de la costa norcentral a inicios de lo conocido como el Formativo Inferior y el inicio y auge de la tradición de los edificios con planta en forma de U12. Es bastante probable que los edificios con planta en $U$ de Huaura sean la expresión de dichos cambios sociales y de la nueva forma de vida en esta época donde, al parecer, el mayor énfasis en la subsistencia y producción de alimentos marinos, como por ejemplo en los sitios de Bandurria o Vichama, se cambió por un modo de vida más enfocado en la producción y consumo de alimentos vegetales gracias a la agricultura13.

Con respecto a la historia o secuencia de la construcción de los edificios, por el momento, se pueden plantear tres posibilidades a la espera de las excavaciones y dataciones absolutas: a) El Edificio B fue el más temprano y, por tanto, la construcción del Edificio A fue posterior, creando un espacio para concentrar una mayor cantidad de personas en su plaza de mayores dimensiones; b) el Edificio A se construyó tempranamente y a este le siguió la construcción del Edificio B, un complejo mucho

9 Algunos autores (por ejemplo Moseley, 1992) señalan a El Paraíso o Chuquitanta, un edificio con planta en $U$ en el valle del Chillón, como el precursor de esta forma arquitectónica en la costa central, pues se considera que pertenecería al periodo Precerámico Tardío. Sin embargo, según los fechados disponibles para el sitio, este sería contemporáneo con otros edificios con planta en forma de U como La Florida (Quilter, 1991a; Pozorski \& Pozorski, 2008: 609).

10 Esto ha sido postulado por Sandweiss et al. (2009). También véase Bird (1987) para el planteamiento de la ocurrencia de un tsunami que provocó el abandono de sitios como Las Haldas a inicios del Formativo.

11 El fechado para el abandono del sitio de Bandurria (Chu, 2008: 141) es de 3440 15 BP (1730 cal a. C.) una fecha que coincide con el final del Precerámico o Arcaico Tardío y los desastres naturales señalados.

12 De hecho, el análisis de la arquitectura monumental del Arcaico o Precerámico Tardío del valle de Huaura de Miguel Aguilar (2006) basado en prospecciones sistemáticas no incluye a los edificios con planta en $\bigcup$ de Huaura. Asimismo, en su análisis se nota claramente que los sitios más extensos del valle durante el Arcaico se encuentran ubicados en el litoral (La Perlita — Vichama según Shady et al., 2009-, Bandurria y Las Salinas).

13 Por ejemplo, en el sitio formativo de Cardal en Lurín, un estudio de la dieta mediante el análisis químico de restos óseos indicó una «mayor dependencia de las plantas terrestres» (Meadors \& Benfer, 2009: 158). 


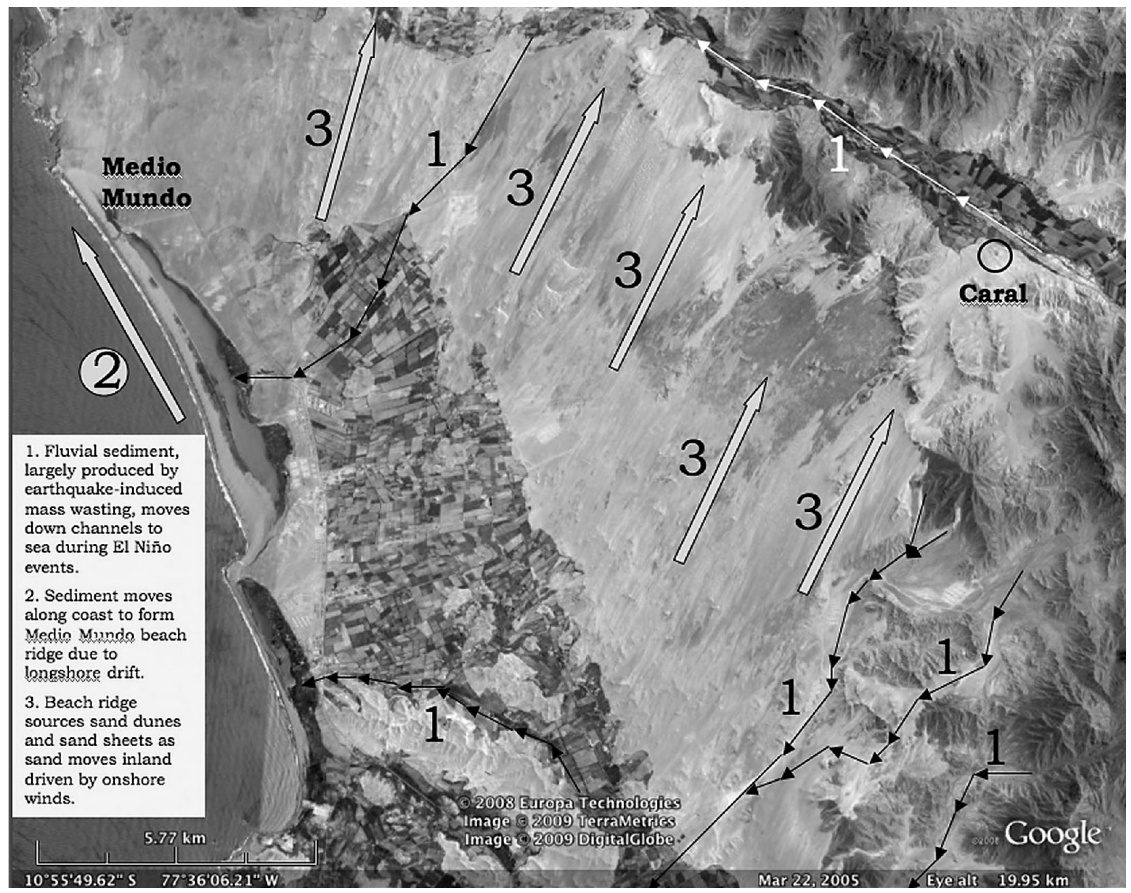

Figura 14 - Ciclo de desastres naturales que incluyeron hacia el final la «arenización» de la zona del valle bajo de Supe y margen norte de Huaura

Según Sandweiss et al., 2009: 136

más restringido para concentrar una menor cantidad de personas; o, C) ambos edificios ( $\mathrm{A}$ y B) fueron construidos simultáneamente dándose una coexistencia de dos edificios morfológicamente similares, aunque con diferentes dimensiones, existiendo solamente una diferenciación funcional y no cronológica.

En las posibilidades a) y b), señaladas anteriormente, no se puede descartar que en algún momento ambos edificios (uno «nuevo»y otro «viejo») funcionaran al mismo tiempo, como se dio en Chavín de Huántar aunque no con las mismas implicancias de restricción social que postula John Rick (2006: 207). Para no ir tan lejos ni alejarse demasiado del tiempo donde se propone que se construyeron los edificios de Huaura se podría remitir a otros edificios con planta en forma de $U$ de la costa central. Para nuestro conocimiento, existen edificios con planta en $U$ en el valle de Lurín como Mina Perdida y Parka que distan algunos unos metros entre sí (Burger \& Salazar, 1994: 112; 2008: fig. 3.8.; Burger, 2009a: 24) y otros en el valle de Chancay: el complejo de San Jacinto (fig. 15), al sur de Huaura. Sin embargo, este último ejemplo presenta dos edificios distantes entre sí por unos 400 m, no estando prácticamente unidos como en el caso de Huaura.

Por ubicación espacial, accesibilidad y volumen, nosotros nos inclinamos por la alternativa b) en la que el Edificio A fue el edificio original en dicha zona y que 


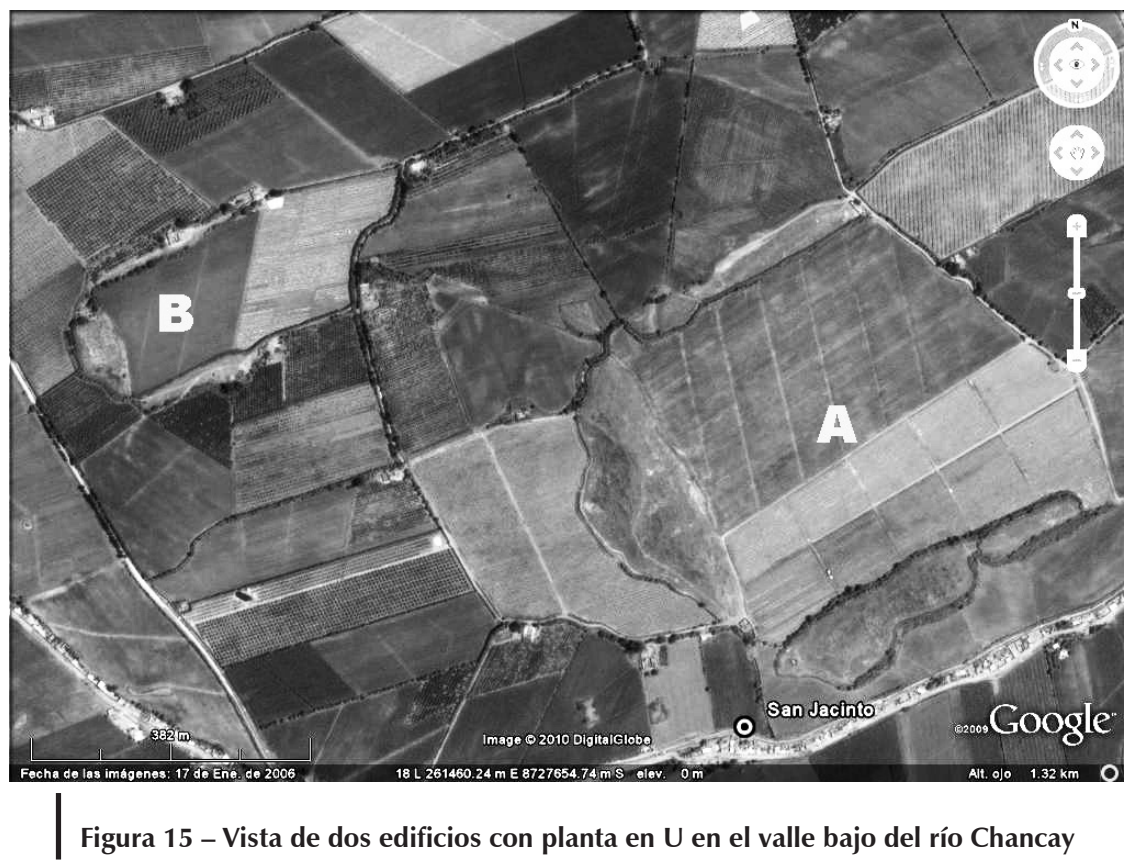

Se puede apreciar un edificio mayor (el sitio de San Jacinto propiamente dicho o 25j 14303) y otro menor (25j 14302) ubicado al noroeste

luego se comenzó a construir el segundo edificio en la parte posterior del edificio principal. En ese sentido, resulta interesante que la plaza principal del Edificio B se comunique directamente con la plaza principal del Edificio A y también conduzca al montículo principal. Por estas cuestiones espaciales, planteamos que el Edificio B se construyó como complemento del Edificio A, de manera que este sirvió como un espacio más restringido. En otras sociedades prehispánicas se piensa que los edificios públicos con espacios más restringidos reflejarían que la sociedad está en un proceso de exclusión social o de asimetría social, privando o restringiendo el acceso que antes era inclusivo a espacios más exclusivos (véase Klarich, 2009). No obstante, también cabría la posibilidad que la construcción de un edificio más pequeño pueda ser el reflejo de que la sociedad que construyó el edificio más grande ya no pudo seguir manteniéndolo o que la plaza de grandes dimensiones ya no fue necesaria. De tal manera, la sociedad habría cambiado un espacio innecesario por un espacio más adecuado a su nueva realidad social sin que eso suponga un cambio sociopolítico o la emergencia de líderes o una elite.

Sin embargo, estos planteamientos ya suponen la incorporación de lógicas o epistemologías a la forma y función de la arquitectura descrita anteriormente y están inspiradas en teorías sociales antropológicas que veremos en mayor detalle a continuación para finalizar con una propuesta propia de los fenómenos sociales que habrían producido ambos edificios. 


\section{PLANTEAMIENTOS PRELIMINARES SOBRE LOS EDIFICIOS CON PLANTA EN FORMA DE U DEL VALLE DE HUAURA Y SUS IMPLICANCIAS PARA LA COSTA CENTRAL Y NORCENTRAL}

Para la mayoría de los arqueólogos y arqueólogas que trabajan en los Andes centrales, la monumentalidad ha sido entendida como un elemento fundamental para establecer el grado de «civilización», «evolución» o «complejidad» de las sociedades que las construyeron. Claramente cada investigador impregnó o deslizó sus lógicas o epistemologías (construyó sus variables e indicadores arqueológicos) para definir qué tipo de sociedad era la causante de las evidencias arquitectónicas que hallaba. De esta manera, desde la época de Max Uhle, se planteó que las sociedades comenzaron a ser organizadas según sus características arquitectónicas, como él mismo hizo cuando colocó a los productores de los kjoekkenmodings o conchales de la costa central peruana en su etapa más temprana y «primitiva» y a las sociedades con arquitectura mayor en una etapa superior (Uhle, 1970 [1910]). Julio C. Tello (1943), hizo lo mismo al colocar a Chavín como la sociedad nuclear o «cultura matriz» de las sociedades andinas. De esta manera, el evolucionismo ha estado casi desde el comienzo detrás de muchas explicaciones arqueológicas en el Perú14. Incluso, esta lógica evolutiva subyace en las representaciones materialistas históricas donde, por ejemplo, desde una perspectiva economicista, la sociedad se va complejizando mediante el desarrollo de las fuerzas productivas (Lumbreras, 2005 [1996]). De esta manera, la emergencia de un liderazgo en los Andes centrales, tanto para algunos arqueólogos procesualistas como para algunos marxistas estaba fundamentada en la economía de la sociedad. Resulta interesante que en ambas posturas, teóricamente contrapuestas, los grupos dominantes («clases sociales dominantes», «especialistas», «sacerdotes», «líderes emergentes», big men, entrepreuners, aggrandizers, etc.) sean vistos como las únicos que pueden llevar adelante a una sociedad y, por consecuencia, los inspiradores y/o responsables principales de las construcciones monumentales. Es decir, la existencia de un grupo social que se ha hecho con el poder político y que utiliza la arquitectura monumental para recrear su posición social. En ambos casos, este proceso siempre sería ascendente hasta llegar a un estado pasando por un estadio intermedio, como por ejemplo, una «jefatura»15.

Con relación a lo anterior, por ejemplo, desde una lógica procesualista, Silva y García planteaban que los edificios con planta en forma de U de la costa central fueron construidas por sociedades del tipo jefatura, ubicándolos dentro de un estadío de evolución social con las implicancias sociales que esto suponía

14 Resulta significativo que ya Rosa Fung (1963) lo expresara de mejor manera que nosotros en su tesis de bachillerato.

15 Categoría que ha sido duramente criticada cuando se utiliza solamente como un peldaño en el esquema evolutivo clasificatorio y no se explica el «contenido» de esa sociedad (véase Yoffee, 2005). 
(Silva \& García, 1997; Carrión, 1998: 247). A su vez, desde su materialismo histórico, para Luis Lumbreras (2005 [1996]: 221; 2007: 638) los «Templos» formativos se explicaban debido a la existencia de un grupo de especialistas que dirigían la sociedad gracias a su conocimiento astronómico o religioso exclusivo y, por eso, marcarían la primera división social del trabajo y establecería una contradicción social entre campesinos y sacerdotes o especialistas religiosos. Estos últimos serían los que dirigirían las ceremonias desde los montículos principales como los edificios con planta en forma de $U$.

En ambos casos, una relación monumentalidad-complejidad social está claramente expresada en la lógica explicativa colocando a los otros miembros de la sociedad en una situación pasiva y/o dependiente con respecto a los cambios que estaban ocurriendo en su propia sociedad. Muchos de esos postulados ahora se cuestionan debido a que en el periodo previo, el Arcaico Tardío, existiría una mayor «complejidad social» e, incluso, un Estado. De esta manera, la visión del periodo Formativo en la costa central ha variado y se explica de otra manera la trayectoria histórica de las sociedades de los valles de la costa central y, sobre todo norcentral, donde se dieron desarrollos sociales importantes tan tempranamente aunque continuos.

En este contexto, resulta interesante que para Richard Burger (2003; 2009a; 2009b) las sociedades que construyeron los edificios con planta en U de Lurín no tengan características estatales o de jefatura, sino que serían más bien comunidades con ausencia de centralización y jerarquía las que construyeron sus edificios por el agregamiento de materiales en momentos concretos durante largos periodos de tiempo16. Es decir, los edificios con planta en forma de $U$ de Lurín serían el producto de prácticas comunales centralizadas en momentos concretos (y no institucionalizados políticamente) como grandes reuniones periódicas relacionadas con una ideología comunal y agraria17. Previamente, Thomas Patterson (1991: 18) ya había planteado una representación similar para la sociedad que construyó el sitio de La Florida en el valle del Rímac, pues, entre sus materiales recuperados no encontraba indicadores arqueológicos que planteasen una asimetría social en el consumo de productos existentes en ese momento18. De esta manera, para ambos investigadores, los grandes edificios con planta en forma de $U$ no tienen por qué ser la expresión material de una sociedad de clases o de una alta complejidad social.

Asimismo, los edificios con planta en forma de $U$ de Lurín no fueron las únicas estructuras arquitectónicas construidas comunitariamente. Los esfuerzos por resguardar estos espacios de reunión se materializaron en la construcción de

16 A pesar de que los cálculos relacionados con la inversión de trabajo social para construir los edificios con planta en $U$ de la costa central arrojan cantidades bastante elevadas y suponen una gran movilización de la fuerza de trabajo, para Burger (1992: 69) estos mismos volúmenes constructivos también podrían ser alcanzados mediante temporadas de trabajo en estaciones concretas del año y, sobre todo, a lo largo de varias generaciones dentro de «sociedades de pequeña escala débilmente estratificadas» (Burger, 1992: 75).

17 Para una crítica al planteamiento «igualitarista» de Burger, véase Kaulicke (2008: 212).

18 También véase el ensayo de Tom Dillehay (2006) para una propuesta similar para las sociedades constructoras de los edificios con planta en forma de $U$ del Formativo. 
grandes muros con funciones de contención y protección19. De tal manera que la «monumentalidad» de los edificios no tenga por qué identificarse (como planteaba Trigger, 1990) como reflejo inmediato de la existencia de una elite que organizaba el trabajo social. En el caso de Lurín se observa claramente la coexistencia de edificios con planta en forma de $U$, una cuestión que haría patente que esos edificios pertenecían a comunidades que compartían espacios muy cercanos 20 o eran visitados por grupos de personas de otras comunidades cercanas o distantes. De esa manera, en otros valles como Chancay (donde también hay edificios de gran magnitud) se acumulan o concentran en grupos (como los relacionados con el de San Jacinto) lo que sustentaría una suerte de crecimiento secuencial y «cancelatorio» de los edificios o de comunidades que mantienen edificios independientes aunque compartan espacios geográficos comunes.

Por lo expuesto anteriormente, se hace necesario investigar en mayor profundidad las características internas de las estructuras arquitectónicas de Huaura para definir exactamente qué tipo de población y las características materiales que se resguardaron en estos edificios.

En ese sentido, como se ha visto, los edificios con planta en $U$ del valle de Huaura comparten la forma de planta y elementos arquitectónicos con otros edificios de la costa central y que recientemente se ha denominado «cultura Manchay», la cual se extendería desde Chancay hasta Lurín (Burger \& Salazar, 2008). Sin embargo, estos edificios tienen demasiados rasgos comunes con los de Huara como para desvincularlos de dicho fenómeno. Más allá de la crítica a la existencia de dicha «cultura arqueológica» también es necesario tomar en cuenta que estos edificios podrían estar representando la materialización de prácticas socioideológicas compartidas por varias comunidades independientes con historias particulares que todavía quedan por definir.

Asimismo, hay que recordar que en esta época además de los sitios monumentales existían otros espacios arquitectónicos «no monumentales» que los rodeaban, poco visibles en superficie21. Actualmente algunos se pueden apreciar como pequeños montículos y otros se pueden recuperar mediante la excavación, como en el caso de Cardal en el valle de Lurín (Burger, 1992) o Cerro Ventana en el valle del Rímac (Silva \& García, 1997). De todas maneras, existe la probabilidad de que algunos no perduraron por estar construidos con materiales livianos y/o desaparecieron por procesos posteriores a su abandono. La comprobación de la existencia de estos

19 Como se dió en Manchay Bajo (Burger, 2003; 2009b).

20 Otra explicación de la existencia de edificios sincrónicos funcionando en un mismo espacio geográfico es la de «Peer Polity» (Mesía, 2000; Vega-Centeno, 2005a: 355) originalmente desarrollado por Renfrew (1986). Según esta explicación la existencia de dos o más edificios, o conjuntos de edificios monumentales contemporáneos, supondría la evidencia de una «competencia» por obtener el control económico y, sobre todo, político de un área o región.

21 En nuestras visitas al edificio con planta en $U$ de Huaura, reconocimos en un hoyo en la parte posterior del montículo principal del Edificio A un perfil donde se podía observar una superposición de capas producto de la actividad humana y que incluía pisos de barro, cenizas y restos botánicos. Esto acusaría la existencia de áreas de actividad humana prehispánica no visibles en la superficie. 
espacios es crucial para entender las prácticas sociales relacionadas con el edificio principal y, por consiguiente, alejar la imagen de nuestras mentes de edificios monumentales aislados en el paisaje, y definir que no son solamente espacios religiosos y/o rituales alejados de la vida «laica» o mundana principalmente.

Estas unidades se han documentado y registrado como aldeas domésticas en el caso de Iguanil para el vecino valle de Chancay donde las investigaciones (Carrión, 2000) indican que se compartían vasijas de estilos similares con las halladas en los edificios con planta en forma de U. Esto también se sustenta para los sitios formativos de litoral como Curayacu (Lanning, 1960; Engel, 1956), Bellavista (Silva \& García, 1997; Cornejo, 2001) o Ancón (Rosas, 2007 [1970]), o de valle medio como Cerro Ventana en Jicamarca, valle del Rímac (Silva \& García, 1997; Kaulicke, 2008: 211), que compartían los mismos estilos cerámicos que los recuperados en los edificios con planta en $U$ cercanos. Sin embargo, no se descarta la posibilidad que estas unidades domésticas se hallen dispersas por el valle con lo que su descubrimiento será más difícil dada su baja visibilidad y los movimientos de tierra agrícola y modificaciones arquitectónicas recientes22.

Más allá, de las limitaciones en su ubicación o preservación, definitivamente es en esos espacios domésticos donde se darían la mayoría de las prácticas socioparentales que suponen la base social; es decir, unidades domésticas donde se da la producción y reproducción de seres humanos y no en la arquitectura monumental (aunque puedan estar muy cercanas a estas). Además, de las diferentes prácticas que satisfacían las necesidades básicas de la sociedad como el consumo de alimentos, también se darían prácticas socioeconómicas como producción y/o transformación de materias primas y eran esos productos los que ayudarían a que la sociedad pueda mantenerse y relacionarse mediante objetos, que no son más que el trabajo social encarnado de la comunidad. He ahí la importancia de reconocer e investigar las características de estas sociedades donde el parentesco básico se gestó y, posteriormente, se proyectaría en las instituciones comunitarias. Regresando a la arquitectura monumental, para nosotros, los edificios con planta en forma de $U$ suponen la materialización de un trabajo social que tiene una forma determinada y supuso la ejecución de una serie de funciones específicas, al margen de los posibles usos que le pueden dar al espacio construido. Si bien, por el momento no se puede definir que prácticas sociales fueron las que motivaron y mantuvieron los edificios con planta en forma de $U$ de Huaura, es plausible plantear que en esos edificios se daban, prioritariamente, prácticas sociopolíticas y socioideológicas (como «residencia de los líderes», escenario para representar performances, hogar del «oráculo», axis mundi, etc.). Sin embargo, no pueden descartarse las prácticas socioeconómicas, pues los edificios con planta en forma de $U$ conforman un lugar de reunión donde se concentran la distribución y consumo de productos creados por la sociedad. Independientemente de la definición de la función

22 Por ejemplo, las prospecciones de Cárdenas (1977b), Miasta \& Merino (1986) y Nelson \& Ruiz (2005) hallaron menos de una veintena de sitios Formativos, muchos de ellos monumentales. 
del montículo principal, las grandes plazas tienen como función principal la reunión de personas, pues los brazos de estos complejos no «crecen» como acumulación de estructuras arquitectónicas superpuestas sino son proyectos públicos y no para el uso original de viviendas, de modo que si se dieron estructuras arquitectónicas importantes y/o alejadas de la vida doméstica o de una elite emergente esta se daría en el montículo principal. Sin embargo, por el momento ninguna investigación conocida sobre los montículos principales ha ofrecido evidencias que las estructuras arquitectónicas en la parte superior de los montículos principales sean unidades domésticas de elite o que hayan sido ocupadas de manera permanente (sean propiedad de algún grupo social)23.

Asimismo, en estos grandes espacios abiertos o plazas, los objetos arqueológicos que acompañan a las prácticas sociales allí realizadas deben tener un rol importante puesto que contienen alimentos o líquidos; son también objetos que guardan un valor simbólico, pues justamente es en esta época que la cerámica ingresa a nuevos espacios alejados de las unidades domésticas y se utilizan como un medio de comunicación importante dentro de las sociedades y entre estas.

En los últimos años, la Antropología y la Etnografía han rescatado a la Arqueología para explicar las manifestaciones sociales relacionadas con los mecanismos que promueven la integración social o la distribución (o redistribución) de productos alimenticios o artefactos 24 que habrían ocurrido probablemente en estas estructuras arquitectónicas. Sin embargo, en tanto explicaciones basadas en la observación de situaciones históricas concretas, se debe estar atento al estudio de la materialidad social de nuestros contextos arqueológicos. Como Siveroni (2006) nos ha recordado, no todo lo que nos «parece» ritual lo es realmente.

Asimismo, si se acepta que el Formativo Inferior es un periodo donde la agricultura se incrementa y, consecuentemente también la población, es necesario incluir los trabajos de canalización de las aguas de los ríos; un trabajo que aunque no deje grandes concentraciones de materiales arqueológicos a diferencia de la arquitectura, también tiene que hacerse colectivamente; representó además en la época prehispánica del Perú una actividad de suma importancia establecida mediante calendarios (obviamente, relacionados con los ciclos agrícolas) y según referencias etnohistóricas, altamente ritualizada. Por lo anterior, resulta interesante anotar que todos los valles de la costa central, sin excepción, tienen al menos uno de estos edificios asociados al fondo del valle, un espacio netamente agrícola en una época de aparente integración social mucho antes de la difusión de la prácticas socioideológicas inspiradas en las ejecutadas en Chavín de Huántar.

En ese mismo sentido, como Williams notó (1980a: 101), resulta interesante que en este momento de construcción monumental, independientemente

${ }^{23}$ Sin excluir que allí también se puedan encontrar indicadores de la realización de actividades más «mundanas» como «almacenes de diversos tipos, ambientes para la producción de bienes como chicha, etc.» (Kaulicke, 2008: 190).

24 Por ejemplo, Mauss (1979 [1924]), Malinowski (2001 [1972]), Sahlins (1963), Rappaport (1999), Dietler \& Hayden (2001), entre otros. Para el Perú véase Dillehay (2005), Kaulicke (2005), VegaCenteno (2005b). 
de la sección del valle en la que se encuentren ubicados los edificios, todos ellos estén orientados con el eje del cauce del río cercano. De esta manera, los edificios serían diseñados y construidos enfrentándose a las avenidas de los ríos, «mirando» hacia las montañas valle adentro y captando y acogiendo entre sus brazos a las personas de una o varias comunidades que comulgaban en sus plazas centrales. Esto contrasta significativamente con los edificios monumentales y más extensos del Precerámico Tardío asociados directamente con el litoral, como Bandurria o Vichama que poseen espacios abiertos entre los montículos sin una orientación clara con relación al valle (Aguilar, 2006; Shady et al., 2009).

En una época en que la agricultura es una solución a la necesidad de reproducir las condiciones materiales de existencia de la sociedad cobra sentido que los edificios principales de estas comunidades tengan como referente máximo al agua, su principal fuente de sustento, cuyo rol fue preponderante en la configuración de sus espacios de reunión. Por consiguiente, los edificios con planta en $U$ son espacios de reunión donde se realizan prácticas socioeconómicas, sociopolíticas y socioideológicas.

Con respecto a las prácticas socioideológicas, ingresando en uno de los diferentes planos desde los cuales se puede interpretar a los edificios con planta en forma de $\mathrm{U}$, la existencia de dos edificios tan cercanos — como ocurre en Chacra Socorro- podría estar indicándonos prácticas socioideológicas dominantes en las que se podría vislumbrar la existencia de una concepción o explicación metafísica dual del mundo. Esta concepción ha sido explorada por Richard Burger y Lucy Salazar (1994)25 para tiempos formativos, donde plantean que ya existirían principios de «dualismo dinámico» u «oposición dual», incluso en edificios con planta en forma de $\mathrm{U}$, contemporáneos con los de Huaral, como los de La Florida en el valle del Rímac, el de Mina Perdida o el de Cardal en el valle de Lurín (Burger \& Salazar, 1994: 110).

La propuesta anterior estaría soportada gracias a otros edificios monumentales contemporáneos como Cardal o Garagay donde el componente ritual o religioso en los montículos principales parece ser importante (Burger, 1992; Ravines \& Isbell, 1976). Sin embargo, creemos que se necesita más trabajo arqueológico para comprender si los principios de una dialéctica andina —en este caso concretados en la arquitectura monumental— son utilizados por las sociedades de la misma manera en diferentes situaciones históricas, a pesar de que existan indicios del compartimiento de una «lógica andina» básica expresada en los edificios principales que, al fin y al cabo, son la concentración de la fuerza de trabajo de una población y, a la vez, una expresión física o encarnación de sus ideas acerca del mundo y su movimiento. Sin embargo, el reconocimiento de dualismos en artefactos (incluyendo aquí a la arquitectura) aislados del conjunto de la materialidad de la sociedad no nos

25 Existen otras propuestas relacionadas con la ideología y cosmovisión de las sociedades formativas de la costa central materializadas en los edificios con planta en forma de $\mathrm{U}$ como las de Tom Dillehay (2006) o Peter Kaulicke (2008), para citar algunos. 
dice si estas fueron parte de sociedades comunitarias, escindidas o con asimetrías sociales, lo cual solo puede ser remediado investigando a diferentes contextos arqueológicos sincrónicos.

Así pues, si bien el modelo de Richard Burger para la costa central relacionada con la tradición de edificios con planta en forma de $U$ y su «cultura Manchay» (Burger, 2003; 2008: 693; 2009b: 192) resulta seductor, todavía queda bastante por definir empíricamente, pues, edificios con la misma apariencia morfológica no tienen por qué suponer la existencia de las mismas prácticas socioeconómicas y/o sociopolíticas en diferentes valles con historias por conocer.

Pese a la extensión regional y temporal de esta tradición arquitectónica en la costa central, esta comenzó a experimentar cambios significativos en su construcción y uso. Así, alrededor del siglo IX ANE en el valle de Lurín se ha reconocido que, junto con la aparición del «fenómeno Chavín», se abandonaron la mayoría de los edificios con planta en forma de $U$ y se construyeron otro tipo de sitios públicos de dimensiones inferiores (Burger, 2003: 98; Dulanto, 2009; Silverman, 2009: 456; Stanish, 2001: 51). En la costa central, otros edificios con planta en forma de U como Garagay, La Florida o San Antonio en el valle del Rímac continuaron en uso durante el Horizonte Temprano o Formativo Medio e incluso parecen compartir artefactos; es decir, ideas asociadas con Chavín de Huántar (Ravines \& Isbell, 1976; Silva \& García, 1997: 207; Kaulicke, 2008: 209; Lumbreras, 2007: 512), de la misma manera, que aldeas contemporáneas de Ancón (Rosas, 2007 [1970]; Lumbreras, 2007: 518, 530), Curayacu (Engel, 1956; Lanning, 1960) o Cerro Ventana (Silva \& García, 1997: 207) siguen siendo ocupadas y se reconoce cerámica con elementos característicos del estilo Chavín. Sin embargo, en la costa norcentral, se iniciaría un proceso de construcción de asentamientos en cumbres de cerro y en secciones escarpadas de los valles (Burger, 1992: 228; Valkenier, 1995; Pozorski, 1987; Proulx, 1973; 1985; Wilson, 1987; 1988; 1995; Chicoine, 2006). Si estos fenómenos locales fueron consecuencia directa de la aparición y creciente importancia de Chavín de Huántar (Burger, 2008: 699), parte de una trayectoria histórica propia o condicionamientos causados por desastres naturales o cambios climáticos (Bird, 1987; Burger, 2003; Sandweiss et al., 2009), es una cuestión que deberá explicarse desde la investigación arqueológica detallada de cada valle.

En el valle de Huaura, alrededor del siglo VIII ANE (2640 90 BP y $2390 \pm 70 \mathrm{BP})$, se inicia la construcción del sitio fortificado de Acaray y otros (Brown, 2008; 2009) ubicados en la cima de los cerros pertenecientes a las primeras estribaciones andinas del valle. En Acaray, se trata de un sitio amurallado construido en la cima de un cerro que se encuentra a unos $70 \mathrm{~m}$ sobre el fondo del valle y a unos $9 \mathrm{~km}$ río arriba de los edificios con planta en forma de $U$ que hemos visto en este artículo. Además, en este lugar el valle se hace más estrecho y controlaría, por lo menos visualmente, el acceso a la ruta hacia la sierra. 
De esta manera, en el valle de Huaura se hace un cambio: de la construcción colectiva de edificaciones monumentales inmediatamente relacionados con las tierras agrícolas y en espacios abiertos en los cuales se convocaban a personas que compartían manifestaciones ideológicas similares, a espacios arquitectónicos emplazados en lugares de difícil acceso, como la cima de cerros improductivos (agrícolamente hablando), con murallas perimétricas y con espacios reducidos de habitación. Esto marca un dramático cambio en las prácticas sociales que debe relacionarse con la existencia de algún tipo de confrontación o conflicto social. Si esto ha sido una respuesta a agresiones o intereses fácticos externos o parte del conflicto social interno de la sociedad de Huaura, es algo que se deberá investigar con mayores trabajos en el área.

\section{COMENTARIOS FINALES}

La arquitectura monumental es una característica sobresaliente y emblemática de la arqueología en los Andes centrales y ha generado una serie de explicaciones sociales con implicancias económicas, políticas e ideológicas muy significativas para la historia del Estado peruano. Por ello, como parte de la trayectoria histórica ha sido relevante entender su profundidad histórica y las formas en las que esta se ha posibilitado. Entender cómo las sociedades pasadas se organizaron socialmente para producirlas ha generado, y seguirá generando, acalorados debates en diferentes espacios, no solamente académicos. Si bien estas discusiones han sido muy importantes, todavía se está lejos de entender la materialidad social del área de la costa norcentral y otras. Más trabajos de campo con diferentes metodologías y epistemologías en diversos sitios o áreas nos ayudarán a comprender mejor la imagen completa de esta época. Por el momento, por tradición de investigación y por cuestiones de conservación, la monumentalidad ha sido beneficiada en nuestras investigaciones y representaciones arqueológicas pero se hace necesario tomar en cuenta y ubicar los restos materiales de los sectores sociales que construyeron y concurrieron a dichos monumentos y ver en qué situación económica y política se hallaban y reconocer los mecanismos por los cuales ellos construían y concurrían a dichos espacios.

Se espera que en un futuro cercano se pueda comenzar a resolver estas interrogantes y llenar este espacio tan relevante para la historia de la costa norcentral, un área que fue testigo de grandes movimientos sociales que desencadenaron la aparición y abandono de grandes proyectos arquitectónicos y que deberemos entender desde la propia materialidad y sus concepciones andinas precapitalistas y no bajo esquemas y enunciados occidentales que han demostrado en los últimos años ser inadecuados para explicar fenómenos sociales con características muy particulares. En ese sentido, los sitios de Huaura, tanto monumentales como no monumentales, jugarán un rol importante en darle sentido histórico a nuestras representaciones arqueológicas. 


\section{Agradecimientos}

Queremos agradecer al profesor Arturo Ruiz Estrada, «padre de la arqueología de Huaura», por sus comentarios sobre la arqueología de este valle. A Kit Nelson, Margaret Brown y Richard Burger por sus apoyos bibliográficos y comentarios. También a Miguel Aguilar y Michiel Zegarra por compartir sus conocimientos sobre los sitios arqueológicos de esta zona. Finalmente, los autores queremos agradecer a los dos revisores externos por sus acertados comentarios y críticas que nos ayudaron a ver nuestro texto desde otra perspectiva.

\section{Referencias citadas}

AGUILAR, M., 2006 - Surgimiento de las Sociedades Complejas en los Andes Centrales. Una Perspectiva desde el Valle de Huaura, Perú; Lima: Universidad Nacional Federico Villarreal. Monografía para optar el título profesional en Arqueología.

ÁlVAREZ, A. \& ESPINOZA, J., 1997 - Mandinga: Un Asentamiento Tipo Aldas en el Valle de Huarmey. Mauq'a Llacta, 1: 27-61.

ASENCIOS, G., 2009 - Investigaciones de las Shicras en el Sitio Precerámico de Cerro Lampay; Lima: Universidad Nacional Mayor de San Marcos. Tesis de Licenciatura en Arqueología.

BAZÁN, A., 2008 - Definiendo la Frontera Sur del Patrón Casmeño. Estudio del Sitio Huaricanga, Valle de Fortaleza; Lima: Escuela Académico Profesional de Arqueología, Universidad Nacional Mayor de San Marcos. Informe de prácticas preprofesionales.

BIRD, R., 1987 - A Postulated Tsunami and Its Effects on Cultural Development in the Peruvian Early Horizon. American Antiquity, 52 (2): 285-303.

BONAVIA, D., 1982 - Los Gavilanes. Mar, Desierto y Oasis en la Historia del Hombre, 512 pp.; Lima: COFIDE, IAA.

BONAVIA, D., 1991 - Perú, Hombre e Historia. De los Orígenes al Siglo XV, 586 pp.; Lima: Edubanco.

BONAVIA, D., 2007 [2003] - Los Orígenes de la Civilización Andina. In: Arqueología y Vida, 1: 139-164; Lima: UNT, IFEA.

BROWN, M., 2008 - War and Social Life in Prehispanic Perú: Ritual, Defense, and Communities at the Fortress of Acaray, Huaura Valley; Illinois: University of Illinois at Urbana-Champaign Department of Anthropology. Tesis doctoral.

BROWN, M., 2009 - Prehispanic Warfare during the Early Horizon and Late Intermediate Period in the Huaura Valley, Perú. Current Anthropology, 50 (2): 255-266.

BURGER, R., 1992 - Chavin and the Origins of Andean Civilization, 248 pp.; Londres: Thames and Hudson.

BURGER, R., 1993 - Emergencia de la Civilización en los Andes, 264 pp.; Lima: Universidad Nacional Mayor de San Marcos.

BURGER, R., 2003 - El Niño, Early Peruvian Civilization, and Human Agency: Some Thoughts from the Lurín Valley. In: El Niño in Peru: Biology and Culture Over 10,000 Years (J. Haas \& M. Dillon, eds.): 90-107; Chicago: Fiediana, Field Museum of Natural History. Botany, 43. 
BURGER, R., 2008 - Chavín de Huántar and Its Sphere of Influence. In: Handbook of South American Archaeology (H. Silverman \& W. Isbell, eds.): 681-703; New York: Springer.

BURGER, R., 2009a - Los Fundamentos Sociales de la Arquitectura Monumental del Periodo Inicial en el Valle de Lurín. In: Arqueología del Período Formativo en la Cuenca Baja de Lurín (R. Burger \& K. Makowski, eds.): 17-36; Lima: PUCP.

BURGER, R., 2009b - El Niño, la Civilización Andina Temprana y la Respuesta Humana: Algunas Reflexiones desde Manchay. In: Arqueología del Período Formativo en la Cuenca Baja de Lurín (R. Burger \& K. Makowski, eds.): 187-208; Lima: PUCP.

BURGER, R. \& SALAZAR, L., 1994 - La Organización Dual en el Ceremonial Andino Temprano: Un Repaso Comparativo. In: El Mundo Ceremonial Andino (L. Millones \& Y. Onuki, eds.): 97-116; Lima: Horizonte.

BURGER, R. \& SALAZAR, L., 2008 - The Manchay Culture and the Coastal Inspiration for Highland Chavin Civilization. In: Chavin: Art, Architecture and Culture (W. Conklin \& J. Quilter, eds.): 85-195; Los Ángeles: Cotsen Institute of Archaeology, UCLA.

BURGER, R. \& SALAZAR, L., 2009 - Investigaciones Arqueológicas en Mina Perdida. Valle de Lurín. In: Arqueología del Período Formativo en la Cuenca Baja de Lurín (R. Burger \& K. Makowski, eds.): 37-58; Lima: PUCP.

CABREL, D., 1996 - Huaura Prehispánica. El Hombre y su Cultura. Los Especiales de Huacho, 75: 5-12; Huacho.

CABREL, D., 2000 - Geoglifos en Vilcahuaura. Raíces, Boletín Cultural Nor Peruano, 2 (8); Lima.

CABREL, D., 2001 - La Cultura Chancay. Gaceta Faustiniana, 2 (5): 28-30; Huacho.

CABREL, D., 2007 - Cañas: Arte rupestre Tardío en el Valle Medio de Huaura. Arkeos, 2 (1); Lima. Disponible en: http://mileto.pucp.edu.pe/arkeos/images/documentos/ articulos/6-art-epar-dcp.pdf

CANZIANI, J., 2009 - Ciudad y Territorio en los Andes. Contribuciones a la Historia del Urbanismo Prehispánico, 549 pp.; Lima: Fondo editorial PUCP.

CÁRDENAS, M., 1977a - Sitios Arqueológicos en Playa Chica-Huacho, Valle de Huaura. Arqueología PUCP: Boletín del Seminario de Arqueología, 19-20: 111-126.

CÁRDENAS, M., 1977b - Informe Preliminar del Trabajo de Campo en el Valle de Huaura. Seminario de Arqueología del Instituto Riva Agüero; Lima: Pontificia Universidad Católica del Perú.

CÁRDENAS, M., 1988 - Arquitectura Prehispánica del Valle de Huaura. In: Arquitectura y Arqueología: Pasado y Futuro de la Construcción en el Perú: 101-114; Chiclayo: Universidad de Chiclayo, Museo Brüning.

CÁRDENAS, M., 2004a - Paraíso 1 de Playa Chica-Huaura: Un Asentamiento del Precerámico y del Formativo. Boletín del Instituto Riva-Agüero, 31: 15-63.

CÁRDENAS, M., 2004b - Visita de Reconocimiento al Sitio Arqueológico de Chacra Socorro. Boletín del Patronato de Defensa del Patrimonio Cultural del Valle de Huaura y Ámbar, 15 (año III): 2-5; Huacho.

CARRIÓN, L., 1998 - Excavaciones en San Jacinto, Templo en U en el Valle de Chancay. Boletín de Arqueología PUCP, 2: 239-250.

CARRIÓN, L., 2000 - Análisis e Interpretación de la Cerámica Formativa del Centro Ceremonial en «U» de San Jacinto. Arqueológicas, 24: 195-262.

CASTRO, P., DE LA TORRE, J. C., ESCORIZA-MATEU, T., GODOY, M. C., LAPI, B., NAVARRO, I. \& ZAVALA, J. C., 2009 - Trabajo, Producción y Cerámica. Sociología de la Alfarería Paracas: Ocucaje y Tajo (Costa Sur de Perú). Estudios Atacameños, 37: 139-155. 
CHICOINE, D., 2006 - Early Horizon Architecture at Huambacho, Nepeña Valley, Peru. Journal of Field Archaeology, 31 (1): 1-22.

CHU, A., 2006 - Arquitectura Monumental Precerámica de Bandurria, Huacho. Boletín de Arqueología PUCP, 10: 91-109.

CHU, A., 2008 - Bandurria, Arena, Mar y Humedal en el Surgimiento de la Civilización Andina, 185 pp.; Huacho: Proyecto Arqueológico Bandurria.

CORNEJO, C., 2001 - El Conchal de Bellavista y su Relación Cronológica con Ancón. Boletín 1. Museo de Arqueología y Antropología de la Universidad Nacional Mayor de San Marcos; Lima. Disponible en: http://sisbib.unmsm.edu.pe/Bibvirtual/ Publicaciones/antropologia/2001_N02/Conchal.htm

CREAMER, W., RUIZ, A. \& HAAS, J., 2007 - Archaeological Investigation of Late Archaic Sites (3000-1800 B.C.) in the Pativilca Valley, Peru. Fieldiana, 40: 1-78.

CRUZADO, E., 2008 - Estudio Preliminar de las Características y Variaciones de la Cerámica del Estilo Huaura; Lima: Escuela de Arqueología, Universidad Nacional Mayor de San Marcos. Informe de prácticas pre-profesionales III.

DIETLER, M. \& HAYDEN, B. (eds.), 2001 - Feasts. Archaeological and Ethnographic Perspectives on Food, Politics and Power, 432 pp.; Washington D.C.: Smithsonian Institution Press.

DILLEHAY, T., 2005 - Pequeñas y Grandes «Voces» en los Foros Públicos del Discurso Andino. Boletín de Arqueología PUCP, 9: 25-43.

DILLEHAY, T., 2006 - Organización y Espacios Sociopúblicos Incipientes: Tres Casos de los Andes. Boletín de Arqueología PUCP, 10: 13-36.

DOLORIER, C. \& CASAS, L., 2009 - Caracterización del Estilo Tricolor Geométrico y Evaluación de Contactos con el Estilo Ychsma. Revista Chilena de Antropología, 20: 169-188.

DULANTO, J., 2009 - Pampa Chica: ¿Qué Sucedió en la Costa Central después del Abandono de los Templos en «U»? In: Arqueología del Período Formativo en la Cuenca Baja de Lurín (R. Burger \& K. Makowski, eds.): 377-399; Lima: PUCP.

ENGEL, F., 1956 - Curayacu, a Chavinoid Site. Archaeology, 9 (2): 98-105.

FUNG, R., 1963 - Arqueología, Ciencia Histórica. Un Ensayo Crítico de los Métodos y las Teorías en la Arqueología Peruana; Lima: Departamento de Etnología y Arqueología, Universidad Nacional Mayor de San Marcos. Tesis de Bachiller.

FUNG, R., 1987 - The Late Preceramic and Initial Period. In: An Overview of Peruvian Prehistory (R. Keatinge, ed.): 67-98; Londres: Cambridge University Press.

HAAS, J. \& CREAMER, W., 2006 - Crucible of Andean Civilization. The Peruvian Coast from 3000 to 1800 BC. Current Anthropology, 47 (5): 745-775.

HAAS, J., CREAMER, W. \& RUIZ, A., 2005 - Power and the Emergence of Complex Polities in the Peruvian Preceramic. In: Foundations of Power in the Prehispanic Andes (K. Vaughn, D. Ogburn \& C. Conlee, eds.): 37-52; Arlington: Archaeological Papers of the American Anthropological Association, Vol. 14.

JACOBS, J., 2000 - Early Monumental Architecture on the Peruvian Coast Evidence of SocioPolitical Organization and the Variation in its Interpretation. Disponible en: http:// www.jqjacobs.net/andes/coast.html

KAULICKE, P., 2000 - Memoria y Muerte en el Antiguo Perú, 387 pp.; Lima: Pontificia Universidad Católica del Perú.

KAULICKE, P., 2005 - Las fiestas y sus residuos: algunas reflexiones finales. Boletín de Arqueología PUCP, 9: 387-402. 
KAULICKE, P., 2008 - La Economía en el Período Formativo. In: Compendio de Historia Económica del Perú. Economía Prehispánica: 137-230; Lima: Banco Central de Reserva del Perú, Instituto de Estudios Peruanos.

KLARICH, E., 2009 - Pukara: Investigaciones de la Temporada 2001 y un Nuevo Modelo para el Desarrollo del Sitio. In: Arqueología del Área Centro Sur Andina (M. Ziółkowski et al., eds.): 283-303; Varsovia: Centro de Estudios Precolombinos, IFEA.

KRZANOWSKI, A., 1991a - Observaciones sobre la Arquitectura y Patrón de Asentamiento de la Cultura Chancay. In: Estudios sobre la cultura Chancay (A. Krzanowski, ed.): 37-56; Cracovia: Universidad Jaguelona.

KRZANOWSKI, A., 1991b - Sobre la Cerámica Chancay del Tipo Lauri Impreso. In: Estudios sobre la cultura Chancay (A. Krzanowski, ed.): 215-242; Cracovia: Universidad Jaguelona.

LANNING, E., 1960 - Chronological and Cultural Relationships of Early Pottery Styles in Ancient Peru; Berkeley: Universidad de California. Tesis para obtener el grado de Doctor en Antropología.

LEÓN, E., 2006 - Radiocarbono y Calibración: Potencialidades para la Arqueología. Arqueología y Sociedad, 17: 67-89.

LEÓN, E., 2007 - Orígenes Humanos en los Andes del Perú, 328 pp.; Lima: Universidad San Martín de Porres.

LUDEÑA, H., 1970 - San Humberto, un sitio formativo en el valle del Chillón. Arqueología y Sociedad, 2: 36-45.

LUDEÑA, H., 1973 - Investigaciones Arqueológicas en el Sitio de Huacoy: Valle del Chillón, 177 pp.; Lima: Programas Académicos de Ciencia Social, Universidad Nacional Mayor de San Marcos. Tesis de Bachiller en Arqueología.

LUMBRERAS, L. G., 2005 [1996] - Acerca de la Aparición del Estado. In: Arqueología y Sociedad (E. Gonzales \& C. del Águila, eds.): 192-229; Lima: MNAAHP, INDEA, IEP.

LUMBRERAS, L. G., 2006 - Un Formativo Sin Cerámica y Cerámica Preformativa. Estudios Atacameños, 32: 11-34.

LUMBRERAS, L. G., 2007 - Chavín. Excavaciones Arqueológicas, 753 pp.; Lima: Universidad Alas Peruanas.

MAKOWSKI, K., 2008 - Andean Urbanism. In: Handbook of South American Archaeology (H. Silverman \& W. Isbell, eds.): 633-657; New York: Springer.

MALINOWSKI, B., 2001 [1972] - Los Argonautas del Pacífico Occidental. Comercio y Aventura entre los Indígenas de la Nueva Guínea Melánesica, 505 pp.; Barcelona: Península.

MATSUZAWA, T., 1978 - The Formative Site of Las Haldas, Peru: Architecture, Chronology and Economy. American Antiquity, 43: 652-673.

MAUSS, M., 1979 [1924] - Ensayo sobre los dones, motivos y formas del cambio en las sociedades primitivas. In: Sociología y Antropología (G. Gurtvich, ed.): 155-263; Madrid: Tecnos.

MEADORS, S. \& BENFER, R., 2009 - Adaptaciones de la Dieta Humana a Nuevos Problemas y Oportunidades en la Costa Central del Perú (1800-800 a.C.). In: Arqueología del Período Formativo en la Cuenca Baja de Lurín (R. Burger \& K. Makowski, eds.): 119 159; Lima: PUCP.

MESÍA, C., 2000 - Anchucaya: Aproximación Teórica sobre un Complejo en «U» en el Valle Medio del río Lurín. Arqueológicas, 24: 45-52.

MIASTA, J. \& MERINO, M., 1986 - Inventario y Catastro de Monumentos Arqueológicos del Valle de Huaura, 151 pp.; Lima: Instituto Nacional de Cultura. 
MOORE, J., 1996 - Architecture and Power in the Ancient Andes. The Archaeology of Public Buildings, 256 pp.; Cambridge: Cambridge University Press.

MOSELEY, M., 1992 - The Incas and Their Ancestors, 272 pp.; Londres: Thames and Hudson.

NARVÁEZ, J., 2006 - Una Visión General del Desarrollo de las Sociedades Prehispánicas del Valle del Rímac. ConTextos, 1: 111-164.

NAVARRO, K., 1993 - Los Complejos con Planta en «U» del Valle de Supe, Costa Central del Perú. Sequilao, 4-5: 19-26.

NELSON, K. \& RUIZ, A., 2005 - Proyecto de Investigación Arqueológica: Valle de Huaura, Perú. Informe Final 2004; Lima. Informe presentado al Instituto Nacional de Cultura.

NELSON, K. \& RUIZ, A., 2010 - The Chancay Tomb of Rontoy, Peru. Antiquity, 84 (323). Disponible en: http://antiquity.ac.uk/projgall/nelson323/

PATTERSON, T., 1985 - The Huaca La Florida, Rímac Valley, Perú. In: Early Ceremonial Architecture in the Andes (C. Donnan, ed.): 59-69; Washington D.C.: Dumbarton Oaks.

PATTERSON, T., 1991 - The Inca Empire. The Formation and Disintengration of a PreCapitalist State, 211 pp.; Oxford: Berg.

PINEDO, O., 2008 - El Salitre (Sulcavilca), Sitio Arqueológico del Valle Bajo de Mala. Algunas Observaciones. In: Arqueología de la Costa Centro Sur Peruana (O. Pinedo \& H. Tantaleán, eds.): 209-230; Lima: Avqi ediciones.

POZORSKI, S., 1987 - Theocracy vs. Militarism: The Significance of the Casma Valley in Understanding Early state formation. In: The Origins and Development of the Andean State (J. Haas, S. Pozorski \& T. Pozorski, eds.): 15-30; Cambridge: Cambridge University Press.

POZORSKI, S. \& POZORSKI, T., 1992 - Early Civilization in the Casma Valley, Peru. Antiquity, 66: 845-870.

POZORSKI, S. \& POZORSKI, T., 2008 - Early Cultural Complexity on the Coast of Peru. In: Handbook of South American Archaeology (H. Silverman \& W. Isbell, eds.): 607631; New York: Springer.

PROULX, D., 1973 - Archaeological Investigations in the Nepeña Valley, Peru. Research report, 292 pp.; Amherst, MA: Department of Anthropology, University of Massachusetts.

PROULX, D., 1985 - An Analysis of the Early Cultural Sequence in the Nepeña Valley, Peru. Research report 25, 359 pp.; Amherst, MA: Department of Anthropology, University of Massachusetts.

PULGAR VIDAL, J., 1976 - Geografía del Perú. Las Ocho Regiones Naturales del Perú, 313 pp.; Lima: Universo.

QUILTER, J., 1991a - Problems with the Late Preceramic of Peru. American Anthropologist, 93 (2): 450-454.

QUILTER, J., 1991b - Late Preceramic Peru. Journal of World Prehistory, 5 (4): 387-438.

RAPPAPORT, R., 1999 - Ritual and Religion in the Making of Humanity, 535 pp.; Cambridge: Cambridge University Press.

RAVINES, R. \& ISBELL, W., 1976 - Garagay: Un Sitio Temprano en el Valle de Lima. Revista del Museo Nacional, XLVI: 253-272.

REISS, W. \& STÜBEL, A., 1880-1887 - Das Todtenfeld von Ancón in Perú. Ein Beitrag zur Kultur und Industrie des Inca-Reiches, 3 tomos; Berlin: A. Asher \& Co. 
RENFREW, C., 1986 - Introduction: Peer Polity Interaction and Socio-Political Change. In: Peer Polity Interaction and Socio-Political Change (C. Renfrew \& J. Cherry, eds.): 1-18; Cambridge: Cambridge University Press.

RICK, J., 2006 - Un Análisis de los Centros Ceremoniales del Periodo Formativo a partir de los Estudios en Chavín de Huántar. Boletín de Arqueología PUCP, 10: 201-214.

ROSAS, H., 2007 [1970] - La Secuencia Cultural del Período Formativo en Ancón, 384 pp.; Lima: Avqi ediciones.

RUIZ, A., 1981 - Reconocimientos arqueológicos en Cerro Colorado. CICITEH. Boletín del Centro de Investigación de Ciencia y Tecnología de Huacho, n. ${ }^{\circ}$ 1; Huacho: Universidad Nacional José Faustino Sánchez Carrión.

RUIZ, A., 1991 - El Entierro de un Músico Prehispánico de Huacho, Valle de Huaura. In: Estudios sobre la cultura Chancay Perú (A. Krzanowski, ed.): 133-153; Cracovia.

RUIZ, A., 2006 - Exploraciones Arqueológicas en la Huaca Choque Ispana, Valle de Huaura. Investigaciones Sociales, 16: 151-169.

SAHLINS, M., 1963 - Poor Man, Rich Man, Big Man, Chief: Political Types in Melanesia and Polynesia. Comparatives Studies in Society and History, 5 (3): 285-303.

SANDWEISS, D., SHADY, R., MOSELEY, M., KEEFER, D. \& ORTLOFF, C., 2009 Environmental Change and Economic Development in Coastal Peru Between 5,800 and 3,600 Years Ago. Proceedings of National Academy of Sciences, 106 (5): 13591363.

SCHEELE, H., 1970 - The Chavin Occupation of the Central Coast of Perú; Cambridge: Department of Anthropology, Harvard University. Tesis doctoral.

SHADY, R., 2006 - La Civilización Caral: Sistema Social y Manejo del Territorio y sus Recursos. Su Trascendencia en el Proceso Cultural Andino. Boletín de Arqueología PUCP, 10: 59-89.

SHADY, R. \& LEYVA, C. (eds.), 2003 - La Ciudad Sagrada de Caral-Supe: Los Orígenes de la Civilización Andina y la Formación del Estado Prístino en el Antiguo Perú, 342 pp.; Lima: Instituto Nacional de Cultura.

SHADY, R. \& RUIZ, A., 1979 - Huaura-Costa Central. Interacción Regional en el Periodo Intermedio Temprano. Arqueológicas, 18: 1-95; Lima.

SHADY, R., CÁCEDA, D., CRISPÍN, A., MACHACUAY, M., NOVOA, P. \& QUISPE, E., 2009 Caral la Civilización Más Antigua de las Américas: 15 Años Develando Su Historia, 138 pp.; Lima: Instituto Nacional de Cultura. Proyecto Especial Arqueológico Caral-Supe.

SILVA, J., 1998 - Una aproximación al Periodo Formativo en el valle del Chillón. Boletín de Arqueología PUCP, 2: 251-268

SILVA, J., 2000 - Origen de las Civilizaciones Andinas. In: Historia del Perú: 15-173; Barcelona: Lexus editores.

SILVA, J. \& GARCÍA, R., 1997 - Huachipa-Jicamarca: Cronología y Desarrollo Sociopolítico en el Rímac. Bulletin de l'Institut Français d'Études Andines, 26 (2):195-228.

SILVA, J. \& JAIME, C., 2000 - Pucará: Un «Templo en U» en la Chaupiyunga del Chillón. Arqueológicas, 24: 27-44.

SILVERMAN, H., 2009 - Comparaciones y Contrastes entre la Costa Sur y la Costa Central del Perú durante el Periodo Formativo. In: Arqueología del Período Formativo en la Cuenca Baja de Lurín (R. Burger \& K. Makowski, eds.): 429-490; Lima: PUCP.

SIVERONI, V., 2006 - Mi Casa es tu Templo. Una Visión Alternativa de la Arquitectura de la Tradición Kotosh. Arqueología y Sociedad, 17: 121-148 
STANISH, C., 2001 - The Origin of State Societies in South America. Annual Review of Anthropology, 30: 41-64.

STUMER, L., 1952 - Investigaciones de Superficie en Caldera (Valle de Huaura). Revista del Museo Nacional, 21: 38-67.

TANTALEÁN, H. \& PINEDO, O., 2004 - Acerca de la Ocupación Inca del Valle de Mala (Cañete, Lima). Arqueología y Sociedad, 15: 135-154.

TELLO, J. C., 1943 - Discovery of the Chavin Culture in Peru. American Antiquity, 9 (1): 135-160.

TRIGGER, B., 1990 - Monumental Architecture: A Thermodynamic Explanation of Symbolic Behaviour. World Archaeology, 22: 119-132.

UHLE, M., 1991 [1903] - Pachacamac. A Reprint of the 1903 edition by Max Uhle, 103 pp.; Philadelphia: The University Museum of Archaeology and Anthropology, University of Pennsylvania.

UHLE, M., 1970 [1910] - Las Civilizaciones Primitivas en los Alrededores de Lima. In: Cien Años de Arqueología en el Perú (R. Ravines, ed.): 379-391; Lima: Instituto de Estudios Peruanos.

VALDEZ, C., 2007 - Chacra Socorro-Huaura. Un Laboratorio Agrícola de 4.000 Años a. C. Disponible en: http://lacomunidad.elpais.com/cesar-evolucion/2007/10/28/chacrasocorro-huaura-un-boratorio-agricola-4-000-anos-a

VALLEJO, F., 2009 - La Problemática de la Cerámica Ychsma: El Estado de la Situación y Algunos Elementos de Discusión. Revista Chilena de Antropología, 20: 133-168.

VALKENIER, L., 1995 - New evidence for Chimu Capac and the Early Horizon Period in the Supe Valley, Peru. Journal of the Steward Anthropological Society, 23: 269-286.

VEGA-CENTENO, R., 2005a - Ritual and Architecture in a Context of Emergent Complexity: A Perspective From Cerro Lampay, a Late Archaic Site in the Central Andes; Tucson: Departamento de Antropología, Universidad de Arizona. Tesis doctoral.

VEGA-CENTENO, R., 2005b - Consumo y Ritual en la Construcción de Espacios Públicos para el Período Arcaico Tardío: El Caso de Cerro Lampay. Boletín de Arqueología PUCP, 9: 91-121.

VEGA-CENTENO, R., 2006 - El Estudio de la Complejidad Social en el Periodo Arcaico Tardío de la Costa Norcentral del Perú. Boletín de Arqueología PUCP, 10: 37-58.

VEGA-CENTENO, R., 2007 - Construction, Labor Organization, and Feasting During the Late Archaic Period in the Central Andes. Journal of Anthropological Archaeology, 26: 150-171.

VEGA-CENTENO, R., 2008 - Estrategias de Excavación y Datación de Arquitectura Pública Temprana. El Caso de Cerro Lampay. Bulletin de I'Institut Français d'Études Andines, 37 (3): 417-439.

VELARDE, L., 1998 - Problemática de los Fechados Carbono 14 y su Calibración: El Caso del Formativo de los Andes Centrales. Arqueología y Sociedad, 12: 11-28.

VELARDE, L., 1999 - La Cronología Absoluta y el Formativo en el Extremo Norte Peruano. Bulletin de la Société Suisse des Américanistes, 63: 127-136.

VON HAGEN, A. \& MORRIS, C., 1998 - The Cities of the Ancient Andes, 240 pp.; Londres: Thames and Hudson.

WILLIAMS, C., 1971 - Centros Ceremoniales Tempranos en el Valle de Chillón, Rímac y Lurín. Apuntes Arqueológicos, 1: 1-4.

WILLIAMS, C., 1972 - La Difusión de los Pozos Ceremoniales en la Costa Peruana. Apuntes Arqueológicos, 2: 1-9. 
WILLIAMS, C., 1980a - Complejos de Pirámides con Planta en U. Patrón Arquitectónico de la Costa Central. Revista del Museo Nacional, XLIV: 95-110.

WILLIAMS, C., 1980b - Arquitectura y Urbanismo en el Antiguo Perú. In: Historia del Perú, tomo VIII: 369-585; Lima: Mejía Baca.

WILLIAMS, C., 1985 - A Scheme for the Early Monumental Architecture of the Central Coast of Perú. In: Early Ceremonial Architecture in the Andes (C. Donnan, ed.): 227240; Washington D. C.: Dumbarton Oaks.

WILLIAMS, C. \& MERINO, M., 1979 - Inventario, Catastro y Delimitación del Patrimonio Arqueológico del valle de Supe; Lima: Instituto Nacional de Cultura.

WILSON, D., 1987 - Reconstructing Patterns of Early Warfare in the Lower Santa Valley: New Data on the Role of Conflict in the Origins of Complex North Coast Society. In: Origins and Development of the Andean State (J. Haas, S. Pozorski \& T. Pozorski, eds.): 56-69; New York: Cambridge University Press.

WILSON, D., 1988 - Prehispanic Settlement Patterns in the Lower Santa Valley, Peru: A Regional Perspective on the Origins and Development of Complex North Coast Society, 590 pp.; Washington D. C.: Smithsonian Institution.

WILSON, D., 1995 - Prehispanic Settlement Patterns in the Casma Valley, North Coast of Peru: Preliminary Results to Date. Journal of the Steward Anthropological Society, 23: 189-227.

YOFFEE, N., 2005 - Myths of the Archaic State: Evolution of the Earliest Cities, States, and Civilizations, 277 pp.; Cambridge: Cambridge University Press.

ZIÓłKOWSKI, M., PAZDUR, M., KRZANOWSKI, A. \& MICHCZYŃSKI, A., 1994 - Andes. Radiocarbon Database for Bolivia, Ecuador and Peru; Warszawa-Gliwice: Misión Arqueológica Andina del Instituto de Arqueología, Universidad de Varsovia, Laboratorio de Radiocarbon de Gliwice del Instituto de Física, Universidad Técnica Silesiana. Disponible en: http://www.softdesign.pl/test/andy/ 